\title{
A Mucoadhesive Electrospun Nanofibrous Matrix for Rapid Oramucosal Drug Delivery
}

\author{
Clare Dott, Charu Tyagi, Lomas K. Tomar, Yahya E. Choonara, Pradeep Kumar, \\ Lisa C. du Toit, and Viness Pillay
}

Department of Pharmacy and Pharmacology, Faculty of Health Sciences, University of the Witwatersrand, 7 York Road, Parktown, Johannesburg 2193, South Africa

Correspondence should be addressed to Viness Pillay; viness.pillay@wits.ac.za

Received 15 July 2013; Accepted 29 August 2013

Academic Editor: Tong Lin

Copyright (C) 2013 Clare Dott et al. This is an open access article distributed under the Creative Commons Attribution License, which permits unrestricted use, distribution, and reproduction in any medium, provided the original work is properly cited.

A nanofibrous matrix system (NFMS), consisting of a drug-loaded nanofiber layer, was electrospun directly onto a polymeric backing film, the latter of which was formulated and optimized according to a 3-level, 3-factor Box-Behnken experimental design. The dependent variables, fill volume, hydroxypropylmethylcellulose (HPMC) concentration, and glycerol concentration, were assessed for their effects on measured responses, disintegration time, work of adhesion, force of adhesion, dissolution area under curve (AUC) at 1 minute, and permeation AUC at 3 minutes. Physicochemical and physicomechanical properties of the developed system were studied by rheology, FTIR, toughness determination, mucoadhesion, and nanotensile testing. Data obtained from the physicomechanical characterization confirmed the suitability of NFMS for application in oramucosal drug delivery. The optimized NFMS showed the drug entrapment of $2.3 \mathrm{mg} / 1.5 \mathrm{~cm}^{2}$ with disintegration time of 12.8 seconds. Electrospinning of drug-loaded polyvinylalcohol (PVA) fibers resulted in a matrix with an exceedingly high surface-area-to-volume ratio, which enhanced the rate of dissolution for rapid oramucosal drug delivery. To corroborate with the experimental studies, the incorporation of glycerol with HPMC and PVA blend was mechanistically elucidated using computer-assisted modeling of the 3D polymeric architecture of the respective molecular complexes to envisage the likely alignment of the polymer morphologies affecting the performance of the nanofibrous device.

\section{Introduction}

Electrospinning has gleaned considerable interest in the field of drug delivery due to its proficiency in producing fibers with eminently small diameters. The process of electrospinning involves applying an electrical potential to a polymer solution in order to produce very fine fibers in the nano- and micrometer size range. When a drop of polymer solution at the end of a capillary tube is subjected to an electrical potential, the drop elongates, becoming conical in shape, and once the electrical field exceeds surface tension, a fiber jet is ejected from the tip of the cone [1-3]. As the fiber jet travels through the atmosphere, the solvent evaporates, and solid polymer fibers are deposited on a grounded collector, closing the gap between the capillary and collector, and hence completing the circuit $[3,4]$. If the polymer concentration, and hence viscosity and chain entanglements, is too low, the jet will break up into droplets before reaching the collector $[5,6]$.
However, as the concentration is increased, the viscosity will increase, and chain entanglements will become sufficient for fiber formation, resulting in a whipping motion of the jet and stretching and thinning of the fiber on application of a potential. Electrospun fibers display a small diameter and extremely high surface area to mass ratio $[7,8]$. This is advantageous in drug delivery as it results in an increase in the total drug release from drug-loaded fibers when compared to cast films of the same composition, which have a considerably smaller surface area $[9,10]$. Furthermore, a large exposed surface area can greatly improve the dissolution rate, and hence bioavailability, of a drug [11-14]. For adequate drug absorption to occur via the buccal mucosa, it is necessary for the drug concentration within the oral cavity to be high. Accelerated disintegration of an orally dissolving drug delivery system results in a high concentration of drug at the surface of absorption and therefore rapid and extensive absorption $[15,16]$. Furthermore, rapid absorption leads to 
expeditious blood levels and hence a prompt onset of action [17-20]. It has been demonstrated that the in vivo availability of a drug administered via the oramucosal route is greatly dependent on the disintegration rate of the drug delivery system [15].

During electrospinning, the polymer chain orientation that occurs during fiber formation has a significant effect on the physicomechanical properties of the nanofibrous matrix that is formed [21]. The fiber diameter has been found to affect the mechanical properties of electrospun materials [22], where fibers with smaller diameters displayed a greater strength but were less pliable than larger fibers [23]. The physicomechanical properties of a material have a significant effect on drug release [24], patient acceptability [25], and residence time at the site of absorption [26, 27]. Due to the relatively short residence time of an oramucosally administered drug delivery system at the site of absorption, mucoadhesion is often required [15]. Mucoadhesive drug delivery systems are advantageous in that the entire system is rendered immobile, an intimate contact between the system and buccal mucosa is created, and a high drug concentration at the absorption surface is achieved $[15,27]$. This results in a reduction in the required drug concentration as well as an improved bioavailability [27]. Thin, mucoadhesive films are favorable for oramucosal drug delivery due to the flexible nature and high contact surface area of such films $[15,28]$.

Statistical optimization, by experimental design, employs mathematical equations and graphic analysis in order to characterize and assess the effects of independent variables on measured responses [29] and was applied to this investigation. In contrast to traditional approaches to formulation optimization, where one variable is assessed at a time, statistical optimization utilizes fewer experimental runs, which is less time consuming and provides a true optimized formulation by a systematic approach [29].

In the work outlined in this study, drug-loaded fibers were electrospun directly onto a statistically optimized polymeric backing film in order to form a porous, rapidly disintegrating nanofibrous matrix system (NFMS) for oramucosal drug delivery. The polymeric backing film was produced according to a Box-Behnken experimental design. The polyvinylalcohol (PVA) electrospun fibers were loaded with model drug, diphenhydramine, in order to assess drug entrapment, release, and permeation characteristics. Drug-loaded films, serving as a comparison, were also prepared according to the same formula as the backing film and using the same constituents as the electrospinning solution. The effects of varying polymeric constituents on drug release, drug permeation, mucoadhesion, and disintegration were also investigated in order to produce an optimized oramucosal drug delivery system

\section{Materials and Methods}

2.1. Materials. Polyvinylalcohol (PVA) (87-89\% hydrolyzed, Mw 13,000-23,000 g/moL) and diphenhydramine (DPH) were purchased from Sigma-Aldrich (St. Louis, MO, USA). Propan-2-ol, glycerol, and citric acid were purchased from
TABLE 1: Polymer concentrations and volumes used in film preparation according to a Box-Behnken design.

\begin{tabular}{lccc}
\hline $\begin{array}{l}\text { Formulation } \\
\text { number }\end{array}$ & $\begin{array}{c}\text { Fill } \\
\text { volume } \\
(\mathrm{mL})\end{array}$ & $\begin{array}{c}\text { HPMC } \\
(\% \mathrm{w} / \mathrm{v})\end{array}$ & $\begin{array}{c}\text { Glycerol (\%w/w of } \\
\text { PVA + HPMC) }\end{array}$ \\
\hline D1 & 40 & 0.50 & 12.5 \\
D2 & 100 & 0.25 & 15.0 \\
D3 & 40 & 0.25 & 15.0 \\
D4 & 70 & 0.25 & 12.5 \\
D5 & 70 & 0.50 & 10.0 \\
D6 & 100 & 0.50 & 12.5 \\
D7 & 40 & 0.25 & 10.0 \\
D8 & 70 & 0.25 & 12.5 \\
D9 & 70 & 0.00 & 10.0 \\
D10 & 100 & 0.00 & 12.5 \\
D11 & 70 & 0.00 & 15.0 \\
D12 & 70 & 0.25 & 12.5 \\
D13 & 70 & 0.50 & 15.0 \\
D14 & 40 & 0.00 & 12.5 \\
D15 & 100 & 0.25 & 10.0 \\
\hline
\end{tabular}

Rochelle Chemicals (Johannesburg, South Africa). Hydroxypropylmethylcellulose (HPMC) was purchased from Colorcon Limited (London, England).

2.2. Preparation of Polymeric Backing Films by Film Casting. Films intended as backing and mucoadhesive layers for electrospun fibers were prepared according to a Box-Behnken experimental design. Polymer solutions were prepared by dissolving glycerol, PVA, and HPMC in a $4: 1$ mixture of deionized water and propan-2-ol. The concentrations and volumes used were as outlined in Table 1 . For all the formulations the PVA concentration was used at $1 \% \mathrm{w} / \mathrm{v}$. Solutions were syringed into rectangular flat-bottomed moulds and left under an extractor at $21^{\circ} \mathrm{C}$ for 48 hours in order that complete solvent evaporation and film formation could occur. For comparative purposes, a DPH-loaded film (FD) containing the same polymeric and plasticizer constituents was prepared.

2.2.1. Experimental Design. A 3-factor Box-Behnken experimental design was generated by Minitab, V15 (Minitab Inc., PA, USA), in order to statistically optimize the polymeric film layer and analyze the effect of formulation variables on system disintegration and drug release. The independent variables $X_{1}, X_{2}$, and $X_{3}$ are outlined in Table 2. $Y_{1}$ through to $Y_{5}$, the dependent variables, were disintegration time, work of adhesion (WA), maximum detachment force (MDF), dissolution area under the curve (AUC) at 1 minute $\left(A U C_{D}\right)$, and permeation $\mathrm{AUC}$ at 3 minutes $\left(\mathrm{AUC}_{\mathrm{P}}\right)$, respectively [30-32].

2.3. Preparation of Nanofibers by Electrospinning. A drugloaded solution for electrospinning was produced by dissolving PVA, citric acid, DPH, and glycerol in a 2:1 mixture of water and propan-2-ol at concentrations of $25 \% \mathrm{w} / \mathrm{v}$, 
TABLE 2: Test parameters employed in biaxial extensibility testing.

\begin{tabular}{lc}
\hline Parameter & Setting \\
\hline Test mode & Compression \\
Pretest speed & $1 \mathrm{~mm} / \mathrm{s}$ \\
Test speed & $1 \mathrm{~mm} / \mathrm{s}$ \\
Posttest speed & $1 \mathrm{~mm} / \mathrm{s}$ \\
Target mode & Distance \\
Distance & $10 \mathrm{~mm}$ \\
Trigger force & $0.5 \mathrm{~N}$ \\
\hline
\end{tabular}

$2 \% \mathrm{w} / \mathrm{v}, 10 \% \mathrm{w} / \mathrm{v}$, and $0.5 \% \mathrm{v} / \mathrm{v}$, respectively. These quantities were based on optimal fiber production, reproducibility, and drug-loading proficiencies as will be explained later in the paper. The solution was placed in a $5 \mathrm{~mL}$ pipette, which was fitted into the adjustable supporting bracket of an electrospinning device. Electrospinning of the solution was performed at $20 \mathrm{kV}$ with a tip-to-collector distance of $11 \mathrm{~cm}$, using a custom-built electrospinning device (RGC Engineering Sales Division, Johannesburg, South Africa) equipped with a voltmeter and MJ Series High Voltage Power Supply (Glassman High Voltage Inc., NJ, USA). Fibers were collected on the polymeric backing film secured on aluminum foillined board which formed the complete NFMS. Samples were cut into sections. For comparative purposes, a film (FE) was prepared with the same drug/polymer ratio as the electrospinning solution.

\subsection{Characterization}

2.4.1. Scanning Electron Microscopy of the Drug-Loaded Fiber Layer. The surface structure of the electrospun fibers was analyzed by images produced by scanning electron microscopy (SEM), using a Phenom Microscope (FEI Company, Hillsboro, OR, USA). Samples were mounted on stubs and sputter-coated with gold prior to examination.

2.4.2. FTIR Spectroscopy. FTIR spectroscopy was performed in order to assess structural changes that may have occurred in the polymeric backbone due to interactions of excipients, drugs, or polymers during film or fiber formation. A Spectrum 100 FT-IR Spectrometer (PerkinElmer Inc., Waltham, MA, USA) was used to assess vibration characteristics of chemical functional groups of samples in response to reactions with infrared light.

\subsubsection{Rheological Studies of the Components of the NFMS.} The rheological properties of polymer solutions and hydrated NFMS, FD, and FE samples were determined with the use of a Haake Modular Advanced Rheometer System (ThermoFisher Scientific, Karlsruhe, Germany). The stress-strain rheological parameters of the polymer solution have an influence on drug release, electrospinning, palatability, and effect on saliva, and they are important factors when considering the desired characteristics of the system. Samples were analyzed by placing the polymer solution or NFMS/film sample, hydrated in $1 \mathrm{~mL}$ simulated saliva ( $\mathrm{pH}$ 6.75), on the sample stage and immersing the spindle in the fluid. The shear rate was ramped from 0 to $500 / \mathrm{s}$, and the shear forces and viscosities of the samples were measured at $37^{\circ} \mathrm{C}$ for the NFMS and film samples and at $25^{\circ} \mathrm{C}$ for the electrospinning solution. The thixotropy of the $25 \% \mathrm{w} / \mathrm{v}$ PVA electrospinning solution was determined by ramping the shear rate from 0 to 50/s over 60 seconds, holding for 60 seconds and then decreasing back to $0 /$ s over 60 seconds. Oscillation studies were carried out by subjecting samples to oscillating stresses or strains. Oscillation measurements were used to determine the storage modulus, $G^{\prime}$, and the loss modulus, $G^{\prime \prime}$, as a function of angular frequency, $\omega$. Oscillation tests provide information on sample elasticity and viscosity related to the applied frequency.

2.4.4. Microenvironmental Surface $p H$ Variation Studies of the NFMS. Extreme changes in $\mathrm{pH}$ on the surface of the matrix can cause irritation to mucous membranes within the oral cavity [33]. Measurement of the surface $\mathrm{pH}$ is therefore essential. Matrices were allowed to swell in contact with $1 \mathrm{~mL}$ of simulated saliva ( $\mathrm{pH}$ 6.75). The surface $\mathrm{pH}$ was measured by glass microelectrode (Mettler Instruments, Giessen, Germany). Measurements were taken after the matrices had been hydrated for 20 seconds and at 1, 3, 5, 10, and 15 minutes thereafter.

\subsubsection{Toughness and Biaxial Extensibility Studies of the NFMS.} Biaxial extensibility was determined from force-distance profiles generated using a TA.XTplus Texture Analyser (Stable Micro Systems, London, England) fitted with a $2 \mathrm{~mm}$ flat cylindrical probe and a $5 \mathrm{~kg}$ load cell. The method of testing the extensibility was based on work by Sibeko and coworkers (2009) [34]. The sample was secured onto a ring assembly with a central hole ( $5 \mathrm{~mm}$ diameter), which was attached to a supportive, hollow, raised platform. The setup was placed such that the cylindrical probe of the textural analyzer was centralized over the hole. The probe was lowered and embedded onto the sample according to the test parameters outlined in Table 2.

2.4.6. Mucoadhesion of the Optimized NFMS and Drug-Loaded Films. Mucoadhesion testing was performed on NFMS sections using a TA.XTplus Texture Analyser (Stable Micro Systems, London, England) fitted with a cylindrical probe. Porcine buccal mucosal tissue was attached to the probe, using rubber bands, and exposed to simulated saliva $(\mathrm{pH}$ 6.75). The NFMS samples were attached to the stage directly below the probe. Mucoadhesion was tested by measuring the maximum detachment force (MDF) and the work of adhesion (WA) $\left(\mathrm{AUC}_{\mathrm{FD}}\right)$ between the buccal mucosa and the samples. The pretest, test, and posttest speeds were 2, 2, and $10 \mathrm{~mm} / \mathrm{s}$, respectively. An applied force of $50 \mathrm{~g}$, a trigger force of $5 \mathrm{~g}$, and contact time of 5 seconds were used for the test.

\subsubsection{Tensile Studies of the Optimized NFMS and Drug-Loaded} Films. The tensile properties of samples were measured using a nanoTensile 5000 (Hysitron Incorporated, Minneapolis, MN, USA). Samples were cut into thin strips and mounted, with cyanoacrylate-based adhesive, onto specially designed mounting brackets held together with rigid strips of cardboard. Once the sample had cured completely, the width, 
length, and thickness were measured with digital calipers. The sample and sample bracket were secured in the upper sample gripper on the nanoTensile (NT) head, and the mass was measured. The NT head was lowered, and the axes were aligned in order to secure the bottom of the sample bracket in the lower sample gripper. The rigid cardboard supports were each cut on the marks in order to prevent the supports from interfering with sample testing. The mounting brackets were moved apart at a constant rate of displacement, and the tensile properties of the sample were measured and recorded.

\subsection{Disintegration Time of the Optimized NFMS and Drug-} Loaded Films. The in vitro disintegration time of NFMS samples and drug-loaded films (FD and FE) was determined according to a modified method based on the United States Pharmacopoeia (USP) method for tablet disintegration testing using a Type PTZ 1 basket-rack assembly disintegration apparatus (Pharma Test, Hainburg, Germany). According to the USP, disintegration is considered to have occurred when there is no longer any solid residue left on the mesh of the basket-rack assembly apparatus (USP 28, 2005). The disintegration medium comprised $150 \mathrm{~mL}$ simulated saliva ( $\mathrm{pH}$ 6.75) placed in a glass jar submerged in a water bath maintained at $37^{\circ} \mathrm{C}$. Samples were cut into sections and placed on the mesh of the basket rack assembly, with a mesh disc placed on top. The basket rack assembly was raised and lowered through a distance of $55 \mathrm{~mm}$ at a frequency of 25 cycles per minute, and the time taken for sample disintegration to occur was determined by observation and recorded.

\subsection{Drug Entrapment of Optimized NFMS and Drug-Loaded} Films. Samples of the NFMS and the two drug-loaded films (FD and FE) were cut into $1.5 \mathrm{~cm}^{2}$ sections, dissolved in simulated saliva ( $\mathrm{pH}$ 6.75), and the drug content of each section was analyzed by UV spectrophotometer (NanoPhotometer, Implen $\mathrm{GmbH}$, Munchen, Germany) at ambient temperature $\left(25^{\circ} \mathrm{C}\right)$ at lambda max of $260 \mathrm{~nm}$.

2.7. In Vitro Drug Release. Standard USP tests and apparatuses for in vitro dissolution and drug release testing require large volumes of fluid, which do not accurately reflect the in vivo conditions in the oral cavity, where there is only a small volume of fluid available for the dissolution of a drug delivery system [35]. A modified drug release testing method was therefore developed for the purposes of this study. In vitro drug release was tested using a $10 \mathrm{~mm}$ long magnet in a $35 \mathrm{~mm}$ diameter petri-dish, placed on a temperaturecontrolled magnetic stirrer. $2 \mathrm{~mL}$ of simulated saliva $(\mathrm{pH}$ 6.75) was placed in the petri-dish, maintained at $37^{\circ} \mathrm{C}$, and stirred at a constant rate to ensure circulation of buffer. NFMS, FD, and FE samples were cut into sections of same dimensions and placed in the buffer. Samples were drawn at $0.083,0.25,0.5,1,3,5,10$, and 15 minutes, analyzed by UV spectrophotometer, and replaced by fresh buffer. As a branded product comparison, the in vitro dissolution testing of Sleepeze-PM tablets was performed using a rotating paddle apparatus (Model 7ST, Caleva, Frankfurt, Germany) and employing $900 \mathrm{~mL}$ phosphate buffered saline (PBS) (pH 6.8, $37^{\circ} \mathrm{C}$ ). Samples were drawn at $1,3,5,10,15,30,60$, and 90 minutes, replaced with fresh buffer, and analyzed by UV spectrophotometer (NanoPhotometer, Implen GmbH, Munchen, Germany).

2.8. Ex Vivo Drug Permeation Studies. Ex vivo drug permeation testing was performed using porcine buccal tissue, which is considered to have a closer resemblance to human buccal mucosa than other animal tissues [36]. Porcine buccal mucosal tissue was obtained from a certified local abattoir and transported, on ice, to the laboratory within 1 hour. Excess tissue was removed; specimens were flash-frozen at $-40^{\circ} \mathrm{C}$ with liquid nitrogen and stored at $-60^{\circ} \mathrm{C}$ until required for use. Frozen specimens were equilibrated in phosphate buffered saline (PBS) ( $\mathrm{pH}$ 7.4) at room temperature to thaw. Sections of mucosa were mounted in Franz Type Diffusion Cells (Perme Gear, Inc., Hellertown, PA, USA) and equilibrated for 0.5 hours at $37^{\circ} \mathrm{C}$ by adding PBS ( $\mathrm{pH}$ 7.4) to both the acceptor and donor compartments. After equilibration, the PBS in the donor compartment was removed and was replaced with an NFMS, FD, or FE sample in simulated saliva (pH 6.75). A $2 \mathrm{mg} / \mathrm{mL}$ DPH in simulated saliva solution was also tested for comparative purposes. Samples were drawn from the acceptor compartment at $0.33,1,2,3,5,10,15$, and 30 minutes and analyzed by UV spectrophotometry, and the removed volume was replaced with fresh PBS. The apparent permeability coefficient $\left(P_{\text {app }}\right)$ and steady state flux $\left(J_{\text {ss }}\right)$ values were calculated using (1) and (2), respectively, as follows:

$$
\begin{gathered}
P_{\text {app }}=\frac{Q}{A \times c \times t}, \\
J_{\text {ss }}=\frac{\Delta M}{A \times \Delta t},
\end{gathered}
$$

where $Q$ is the total amount of drug permeated during the testing time $(\mu \mathrm{g}), A$ is the diffusional area $\left(\mathrm{cm}^{2}\right), c$ is the initial drug concentration in the donor compartment $(\mu \mathrm{g} / \mathrm{mL}), t$ is the total time that the experiment was run for (seconds), and $\Delta M$ is the amount of drug that had permeated through the mucosal tissue during time $\Delta t$.

\subsection{Atomistic Molecular Structural Mechanics Simulations.} Molecular mechanics computations in vacuum, which included the model building of the energy-minimized structures of multipolymer complexes, were performed using the HyperChem 8.0.8 Molecular Modeling System (Hypercube Inc., Gainesville, FL, USA) and ChemBio3D Ultra 11.0 (CambridgeSoft Corporation, Cambridge, UK) [37]. The PVA decamer was drawn using ChemBio3D Ultra in its syndiotactic stereochemistry as a $3 \mathrm{D}$ model, whereas the structure of HPMC (4 saccharide units) was built from standard bond lengths and angles using sugar builder module on HyperChem 8.0.8. The oligosaccharide length for the polysaccharide chain was determined on the basis of equivalent grid surface area covered by the polysaccharide so that the inherent stereoelectronic factors at the interaction site can be perfectly optimized. The set of low-energy conformers that were in equilibrium with each other was identified and 
portrayed as the lowest energy conformational model. The structure of glycosylated mucopeptide analogue (MUC) was generated using sequence editor module on HyperChem 8.0.8. The glycosylation was carried out at the threonine and serine amino acid residues. The structure of glycerol (GLY) was built up with natural bond angles as defined in the Hyperchem software. The models, initially minimized using the $\mathrm{MM}+$ Force Field, were energetically optimized using the AMBER 3 (Assisted Model Building and Energy Refinements) Force Field. The conformer having the lowest energy was used to create the polymer-polymer complexes. A complex of one molecule with another was assembled by disposing them in a parallel way, and the same procedure of energy-minimization was repeated to generate the final models. Full geometry optimizations were carried out in vacuum employing the Polak-Ribiere conjugate gradient method until an RMS gradient of $0.001 \mathrm{kcal} / \mathrm{moL}$ was reached. Force field options in the AMBER (with all hydrogen atoms explicitly included) and $\mathrm{MM}+$ (extended to incorporate nonbonded cut-offs and restraints) methods were the HyperChem 8.0.8 defaults. For calculations of energy attributes, the force fields were utilized with a distance-dependent dielectric constant scaled by a factor of 1 . The 1-4 scale factors are the following: electrostatic 0.5 and van der Waals 0.5. Invariant factors common to mathematical description of binding energy and substituent characteristics have been ignored [37].

\section{Results and Discussion}

3.1. Response Optimization. All the NFMS prepared through inclusion of 15 different formulations of polymer backing film were analyzed in terms of disintegration time, work of adhesion (WA), maximum detachment force (MDF), area under the curve $\left(\mathrm{AUC}_{\mathrm{D}}\right)$ at 1 minute, and area under the curve $\left(\mathrm{AUC}_{\mathrm{P}}\right)$ at 3 minutes which are graphically represented in Figure 1.

Response optimization was performed using Minitab, V15 (Minitab Inc., PA, USA). The film formulation was optimized according to the measured responses. Maximizing and minimizing responses, where appropriate, resulted in a low desirability for the optimized formulation, and the values were therefore targeted within the limits of acceptability. The final optimization plot revealed a composite desirability of $95.23 \%$. Tables 3 and 4 display the fitted values acquired from formulation optimization with the observed experimental values for the various responses.

For optimized film preparation, polymer solutions were prepared by dissolving $136.5 \mathrm{mg}$ of glycerol, $794 \mathrm{mg}$ of polyvinylalcohol (PVA), and $116 \mathrm{mg}$ of hydroxypropylmethylcellulose (HPMC) in $79.39 \mathrm{~mL}$ of a $4: 1$ mixture of deionized water and propan-2-ol.

3.2. Physical Dimensions of the Films and Fiber Layer. The films produced were even, thin, transparent, and pliable. The fibers formed a white layer on the films. The NFMS backing layer film was $80 \mu \mathrm{m}$ thick, while the complete NFMS was $460 \mu \mathrm{m}$ thick, and hence the fiber layer was $380 \mu \mathrm{m}$ thick. The
TABLE 3: Targeted responses for constrained optimization of the film formulation.

\begin{tabular}{lccc}
\hline Response & Lower & Target & Upper \\
\hline Disintegration time (seconds) & 12 & 13 & 20 \\
Work of Adhesion (mJ) & 0.3 & 0.4 & 0.7 \\
Maximum detachment force (N) & 0.2 & 0.3 & 0.45 \\
AUC $_{\mathrm{D}}$ at 1 minute & 0.3 & 0.35 & 0.45 \\
AUC $_{\mathrm{P}}$ at 3 minutes & 1.6 & 1.9 & 2 \\
\hline
\end{tabular}

TABLE 4: Fitted and experimental values for the optimization responses.

\begin{tabular}{lccc}
\hline Response & $\begin{array}{c}\text { Fitted } \\
\text { value }\end{array}$ & $\begin{array}{c}\text { Experimental } \\
\text { value }\end{array}$ & Desirability \\
\hline $\begin{array}{l}\text { Disintegration time } \\
\text { (seconds) }\end{array}$ & 13.2457 & 12.8 & $96.6 \%$ \\
$\begin{array}{l}\text { Work of adhesion (mJ) } \\
\text { Maximum }\end{array}$ & 0.3885 & 0.335 & $86.2 \%$ \\
$\begin{array}{l}\text { Detachment force (N) } \\
\text { AUC }_{\mathrm{D}} \text { at 1 minute }\end{array}$ & 0.3043 & 0.2705 & $88.9 \%$ \\
AUC $_{\mathrm{P}}$ at 3 minutes & 0.3491 & 0.4179 & $83.5 \%$ \\
\hline
\end{tabular}

FE film was $110 \mu \mathrm{m}$ thick, and the FD film was approximately $90 \mu \mathrm{m}$ thick but was somewhat uneven in places.

3.3. Scanning Electron Microscopy. SEM analysis revealed that the fibers produced were randomly arranged having uniform diameters on average. The fiber diameter was approximately $0.36 \mu \mathrm{m}$, and the average visible pore size ranged between approximately 0.69 and $1.91 \mu \mathrm{m}$, as depicted in Figure 2.

3.4. FTIR Spectroscopy. FTIR analysis was performed in order to determine whether any chemical changes occurred to the drug and/or polymer during the process of electrospinning. The FTIR spectra for the DPH-loaded fiber layer (DF), DPH, and non-drug-loaded PVA placebo fibers $(\mathrm{PF})$ are depicted in Figure 3. The broad $\mathrm{O}-\mathrm{H}$ stretching vibration of PVA can clearly be seen for both DF and PF at $3295 \mathrm{~cm}^{-1}$. DPH and DF both show a small peak at $3033 \mathrm{~cm}^{-1}$, characteristic of the phenyl groups present in the DPH molecule (Figure 3). The phenyl groups are also identified by the presence of large peaks at $755 \mathrm{~cm}^{-1}$ and $702 \mathrm{~cm}^{-1}$ in both profiles where DPH was present. The peak associated with the stretching vibration of the alkoxy substituent in the DPH molecule at $2955 \mathrm{~cm}^{-1}$ is obscured by the slightly broader band of the alkyl group of the PVA molecule at $2913 \mathrm{~cm}^{-1}$ in the DF spectrum, which can also be seen in the PF spectrum. The broad peaks at $2594 \mathrm{~cm}^{-1}, 2524 \mathrm{~cm}^{-1}$, and $2487 \mathrm{~cm}^{-1}$ in the DPH spectrum, representative of the tertiary amine group, are also visible in the DF spectrum, but not in the PF spectrum. The peak at $1598 \mathrm{~cm}^{-1}$, indicating the absorption from the phenyl groups, is visible in both the DPH and DF spectra. From the FTIR data, it can therefore be deduced that no significant chemical changes occurred to the drug during solution preparation and electrospinning. 


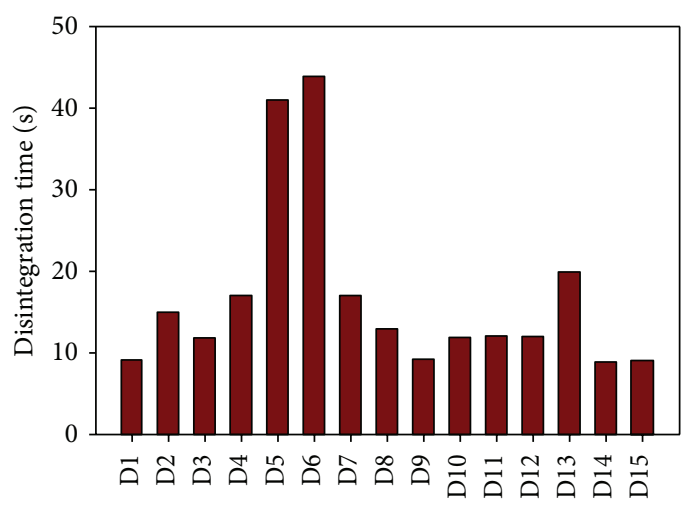

(a)

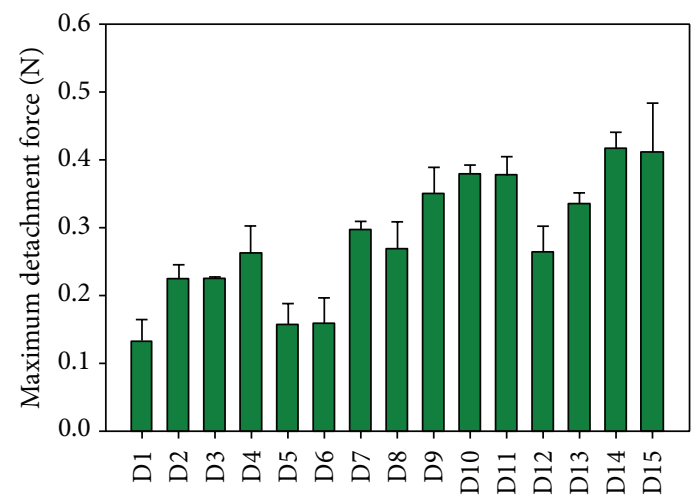

(c)

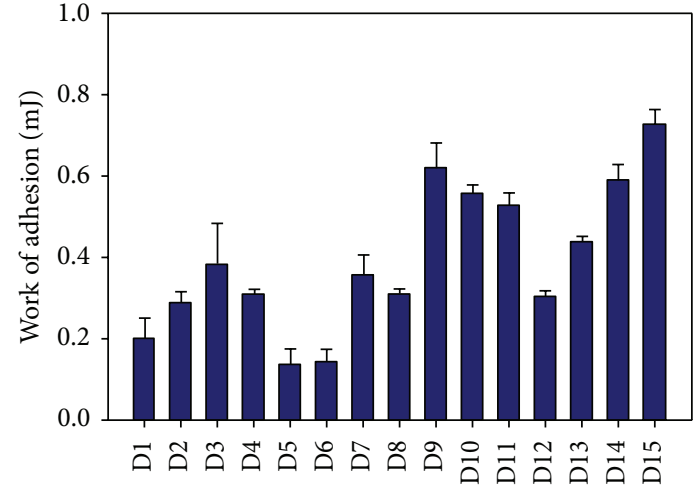

(b)

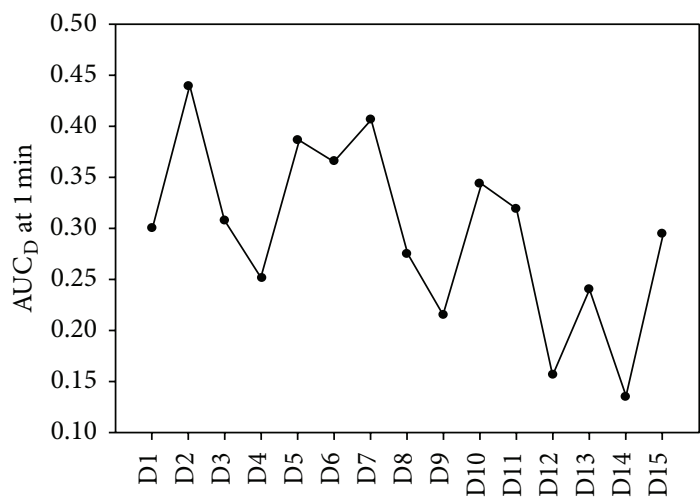

(d)

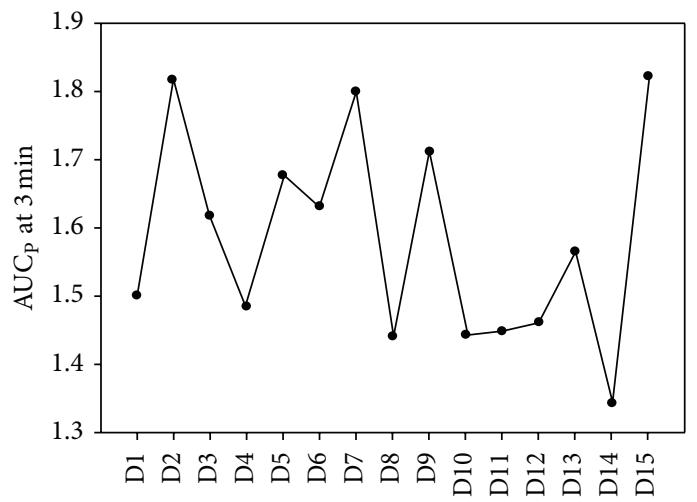

(e)

FIGURE 1: The 15 experimental design formulations depicting (a) average disintegration times, (b) average work of adhesion (WA), (c) average maximum detachment force (MDF), (d) $\mathrm{AUC}_{\mathrm{D}}$ at 1 minute, and (e) $\mathrm{AUC}_{\mathrm{P}}$ at 3 minutes.

\subsection{Rheological Studies of the Components of the NFMS}

3.5.1. Formulations. The rheological properties of a hydrated sample play an important role in the retention of that sample within the buccal cavity. The hydrated film and NFMS samples were investigated for the effect of an increasing shear rate $(\dot{\gamma})$ on shear force $(\tau)$ and viscosity $(\eta)$. The average values over the shear rate range for these parameters are outlined in Table 5. Linear rheological profiles are depicted in Figure 4. The FE film (Figure 4(c)) exhibited an exceedingly larger average viscosity and shear force than the NFMS (Figure 4(a)) and FD film (Figure 4(b)), which correlates with the greater mucoadhesive properties and slower disintegration rate evinced by this film. However, such a high viscosity may result in an unpleasant mouthfeel in vivo [38]. The large disparity between the parameters of the NFMS and FE film may be due to the more rapid disintegration rate of the former. Nevertheless, the rheological properties of the NFMS suggest that it would have an adequate retention time, which is in agreement with the mucoadhesion data reported in a later section.

3.5.2. Electrospinning Solution. The rheological properties of a solution employed for electrospinning can have a substantial effect on the process of electrospinning as well as the 


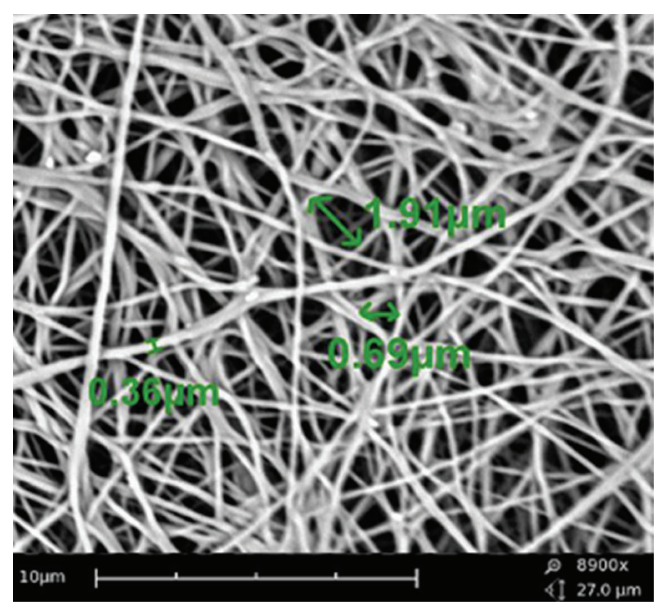

FIGURE 2: SEM image of the electrospun fiber layer, showing average fiber diameter of $0.36 \mu \mathrm{m}$ and visible pore size of between 0.69 and $1.91 \mu \mathrm{m}$.

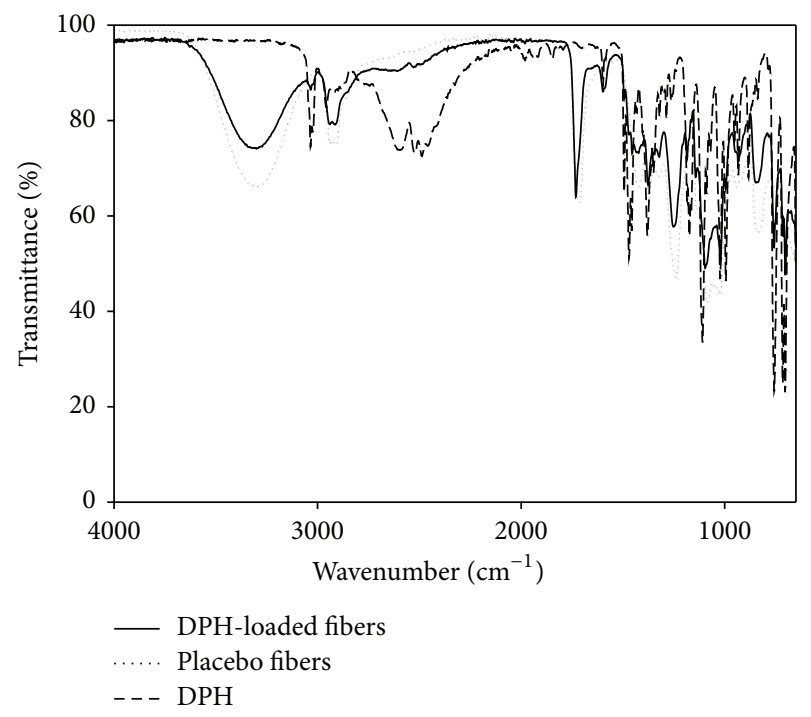

FIGURE 3: FTIR profiles of the drug-loaded fibers (DF), placebo fibers (PF), and DPH.

TABLE 5: Average rheological parameters of the NFMS, FD film, and FE film in $1 \mathrm{~mL}$ simulated saliva ( $\mathrm{pH}$ 6.75).

\begin{tabular}{lccc}
\hline Sample & Shear rate $(1 / \mathrm{s})$ & Shear force $(\mathrm{Pa})$ & Viscosity $(\mathrm{mPa} \cdot \mathrm{s})$ \\
\hline NFMS & 254.3 & 7.44 & 32.29 \\
FD & 252.3 & 7.39 & 30.49 \\
FE & 253.2 & 82.71 & 1616.67 \\
\hline
\end{tabular}

quality and morphology of fibers that are formed. The degree of polymer chain entanglements, and hence the polymer concentration, has a considerable influence over the viscosity of a solution. The actual conformation of individual polymer chains also has a significant influence on solution viscosity, considering that solutions containing coiled chains have a lower viscosity than those with extended chains [39]. It is therefore important to investigate the rheological properties of polymeric solutions employed in electrospinning. The $25 \% \mathrm{w} / \mathrm{v}$ PVA solution that was electrospun to form the fiber layer of the NFMS was analyzed for responses to rheological stresses, both linear and oscillating. The average shear force $(\tau)$ and viscosity $(\eta)$ were $186.40 \mathrm{~Pa}$ and $737.5 \mathrm{mPa} \cdot \mathrm{s}$, respectively, for an average shear rate $(\dot{\gamma})$ of $252.3 /$ s. Figure 5 displays the rheological profile. The linear rheological properties of the $25 \% \mathrm{w} / \mathrm{v}$ solution were deemed acceptable for electrospinning because adequate fiber formation occurred at that polymer concentration.

Thixotropy is observed when the viscosity of a material, that was at rest, decreases on exposure to a mechanical stress and consequently increases again upon removal of the stress. The thixotropy of the $25 \% \mathrm{w} / \mathrm{v}$ PVA electrospinning solution was determined by calculating the difference between the AUC values of the increasing shear and decreasing shear rate curves and was determined to be $-1.229 \mathrm{~Pa} \cdot \mathrm{s}^{-1}$. This difference is relatively small when compared to the average AUC, which was $757.4 \mathrm{~Pa} \cdot \mathrm{s}^{-1}$, and it was deduced that the electrospinning solution underwent adequate thixotropic recovery. Figure 5(b) displays the thixotropy curve for the $25 \%$ PVA solution. The curves of shear stress as a function of shear rate (blue line) for both increasing and decreasing rates follow an almost identical path and appear as one thick line, suggesting a favorable recovery of the sample.

Viscoelasticity is an important factor to be considered for the electrospinning of a polymer solution as the polymer is required to be stretched in order to produce fibers. It is necessary for the elastic properties of a solution to be great enough so that the fiber jet will not break up before reaching the collector surface. Oscillation rheology testing is a useful tool for assessing the viscoelastic behavior of materials intended for electrospinning. The yield stress $\left(\tau_{o}\right)$ was determined for the $25 \% \mathrm{w} / \mathrm{v}$ PVA electrospinning solution at $25^{\circ} \mathrm{C}$ by measuring the deformation $(\gamma)$ over a range of controlled stress $(\tau)$. The average yield stress was $0.3782 \mathrm{~Pa}$ and the rheological plot is depicted in Figure 5(c). In order to determine the viscoelastic region of the $25 \% \mathrm{w} / \mathrm{v}$ PVA electrospinning solution, a stress sweep was performed at various frequencies to ascertain the yield point. The yield point was found to be $6.36 \mathrm{~Pa}$ at a frequency of $0.1 \mathrm{~Hz}$. A frequency sweep was performed in order to determine the stability of the $25 \% \mathrm{w} / \mathrm{v}$ PVA solution. The frequency of oscillations ranged from 8 to $0.008 \mathrm{~Hz}$ at a constant stress. The resulting plot is presented in Figure 5(d).

3.6. Microenvironmental Surface $p H$ Variation of the NFMS. It has been observed that extreme changes in surface $\mathrm{pH}$ may cause damage to mucosal surfaces [40]. The evaluation of surface $\mathrm{pH}$ variation is therefore an important factor to consider for oramucosal drug delivery system. The surface $\mathrm{pH}$ values of NFMS ranged between 6.63 and 6.75 over the 15 minutes in which measurements were taken (Figure 6). There was an initial drop in $\mathrm{pH}$ to 6.63 at the 20 second time point, possibly due to dissolution and subsequent solubilization of citric acid, which was employed in the formulation as a tastemasking component. At the 3 minute time point, the $\mathrm{pH}$ had 


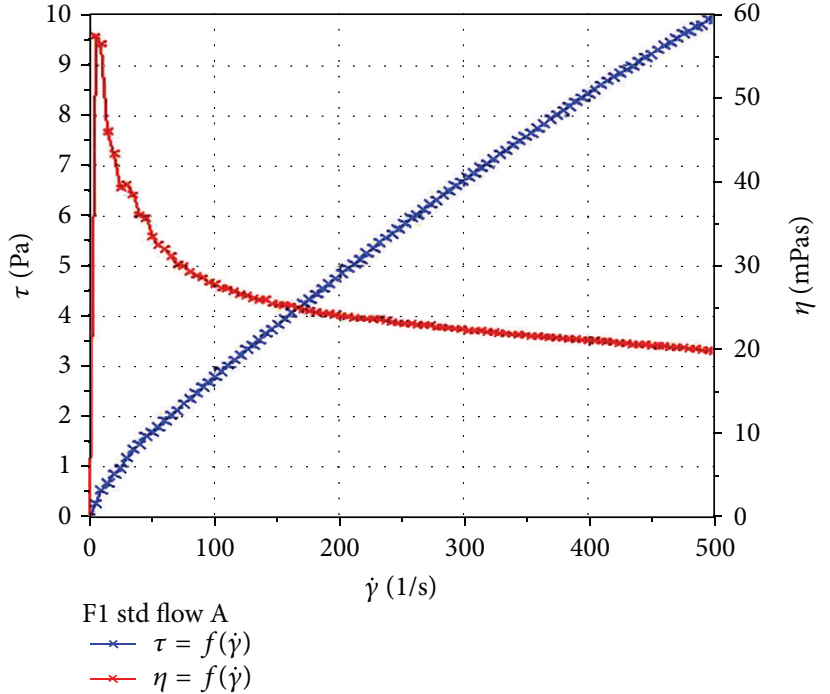

(a)

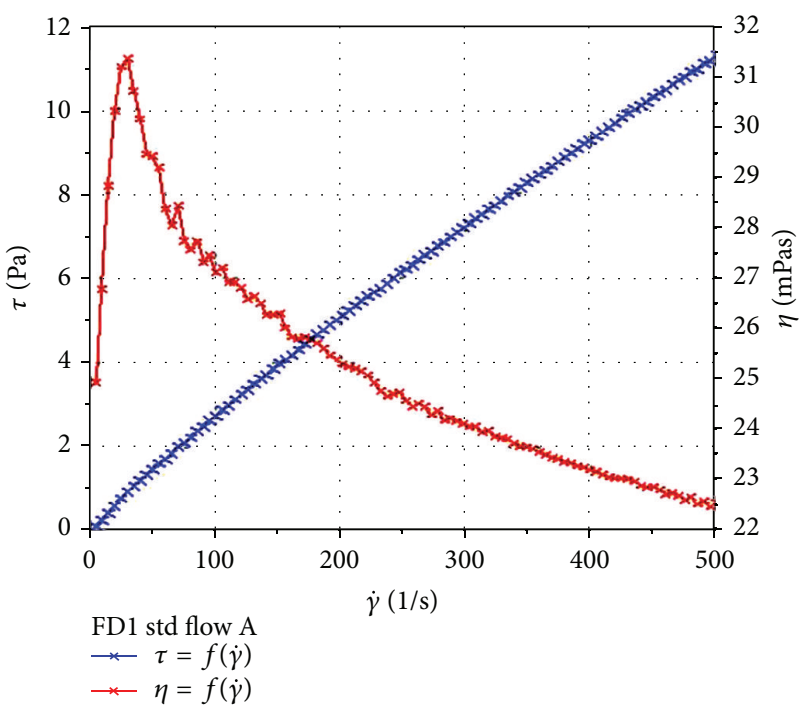

(b)

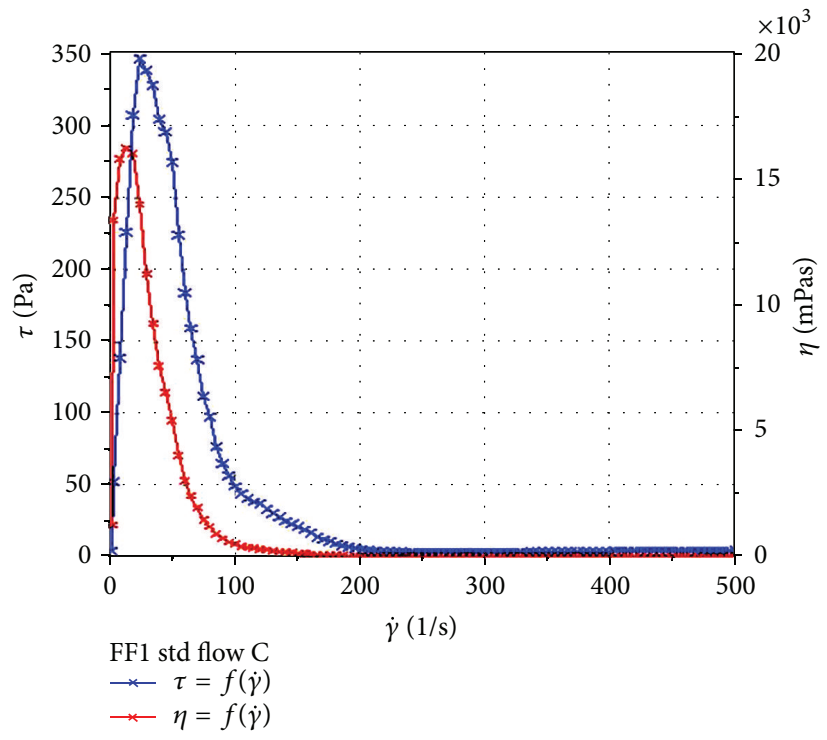

(c)

FIGURE 4: Linear rheological profiles of the (a) NFMS, (b) FD film, and (c) FE film.

increased to 6.73 , which may be due to the buffering effect of the simulated saliva or the dissolving of the polymeric components of the formulation. The variation of $\mathrm{pH}$ was less than 0.5 units and was considered acceptable for an oramucosally administered drug delivery system as it can be deduced that minimal irritation to the buccal mucosa would occur.

3.7. Toughness and Biaxial Extensibility Studies of the NFMS. Extensibility is the degree of extension or stretching that a material can withstand before fracture occurs; polymer linkages have a substantial effect on the physicomechanical strength of materials. The maximum force $\left(F_{\max }\right)$ and distance $\left(D_{\max }\right)$ values for the NFMS, optimized polymer backing film of the NFMS (NFMS film), FD film, and FE film were plotted and are presented in Figure 7. The complete
NFMS was found to be slightly stronger than the NFMS film $\left(F_{\max }=5.29 \mathrm{~N}\right.$ and $5.17 \mathrm{~N}$, resp.), but also less extensible $\left(D_{\max }=4.435\right.$ and $4.957 \mathrm{~mm}$, resp.). It can therefore be deduced that the presence of electrospun fibers resulted in a slight increase in film strength and a decrease in extensibility. When electrospun fibers are produced, there is a thinning and extending process that takes place, and this may result in the fibers being less extensible than the film. The presence of drug in the polymer backing film (FD) brought about a decrease in both $F_{\max }$ and $D_{\max }$. This may also partially explain the reduction in extensibility with the presence of a drug-loaded fiber layer. The FE film had a significantly larger $F_{\max }$ and $D_{\max }$ than the NFMS, which may be due to the absence of the more rigid polymer, HPMC, and formation by film casting, which does not result in thinning, of the former. 


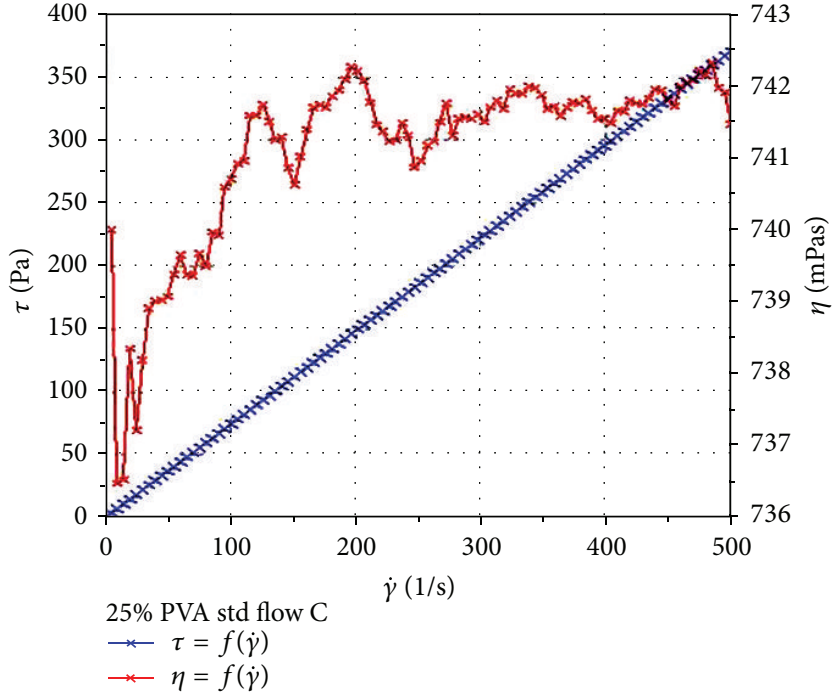

(a)

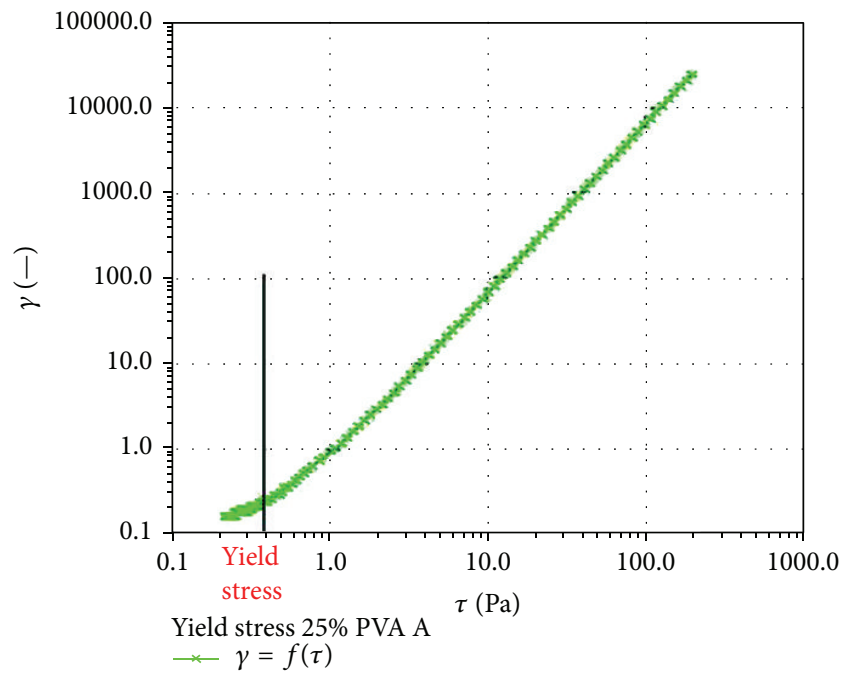

(c)

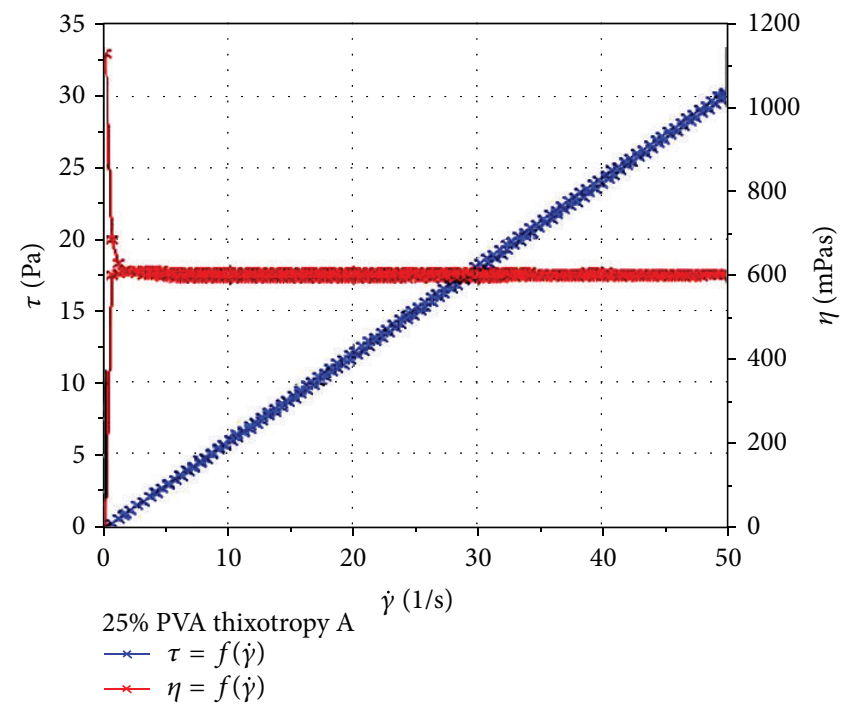

(b)

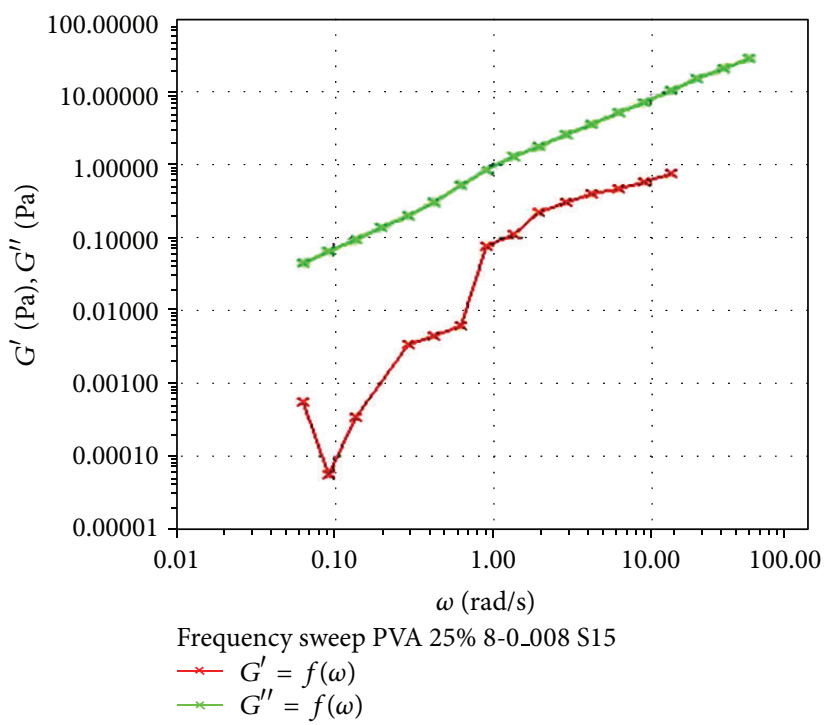

(d)

FIGURE 5: (a) Linear rheological profile of 25\% w/v PVA electrospinning solution, (b) thixotropy curve for the 25\% w/v PVA solution used for electrospinning, (c) rheology plot depicting the yield stress (at $0.3782 \mathrm{~Pa}$ ) of a $25 \% \mathrm{w} / \mathrm{v}$ PVA solution intended for electrospinning, and (d) stress sweep of $25 \% \mathrm{w} / \mathrm{v}$ PVA solution intended for electrospinning.

TABLE 6: Experimental values obtained from nanotensile analysis.

\begin{tabular}{lccccc}
\hline Sample & $\begin{array}{c}\text { Young's } \\
\text { modulus } \\
(\mathrm{MPa})\end{array}$ & $\begin{array}{c}\text { Yield } \\
\text { stress } \\
(\mathrm{MPa})\end{array}$ & $\begin{array}{c}\text { Ultimate } \\
\text { strength } \\
(\mathrm{MPa})\end{array}$ & $\begin{array}{c}\text { Ultimate } \\
\text { strain }\end{array}$ & $\begin{array}{c}\text { Toughness } \\
\left(\mathrm{J} / \mathrm{cm}^{3}\right)\end{array}$ \\
\hline Fiber layer & 26.09 & 0.49 & 2.98 & 0.227 & 0.38 \\
NFMS & 36.01 & 1.675 & 3.33 & 0.242 & 0.62 \\
film & & & & & 0.238 \\
NFMS & 30.31 & 1.18 & 2.79 & 0.48 \\
FD & 56.35 & 1.13 & 2.73 & 0.314 & 0.71 \\
FE & 20.34 & 1.10 & 3.52 & 0.731 & 2.10 \\
\hline
\end{tabular}

3.8. Tensile Properties by Nanotensile Testing. The stressstrain relationship of a material is highly dependent on the flexibility of the polymer chains and the strength of the material. When only a small amount of stress is required to produce a large amount of strain, the material is considered to be flexible, and Young's modulus, which is the slope of the linear portion of the stress-strain curve, will be relatively small. The average experimental values for Young's modulus $(E)$, yield stress $\left(\sigma_{y}\right)$, ultimate strength $\left(\sigma_{u}\right)$, ultimate strain $\left(\varepsilon_{u}\right)$, and toughness $\left(u_{f}\right)$ are outlined in Table 6 . The samples tested were the fiber layer of the NFMS (Figure 8(a)), the NFMS film (Figure 8(b)), the complete NFMS (Figure 8(c)), the FD film (Figure $8(\mathrm{~d})$ ), and the FE film (Figure 8(e)). The drug-loaded fiber layer exhibited the smallest yield stress, ultimate strain, 


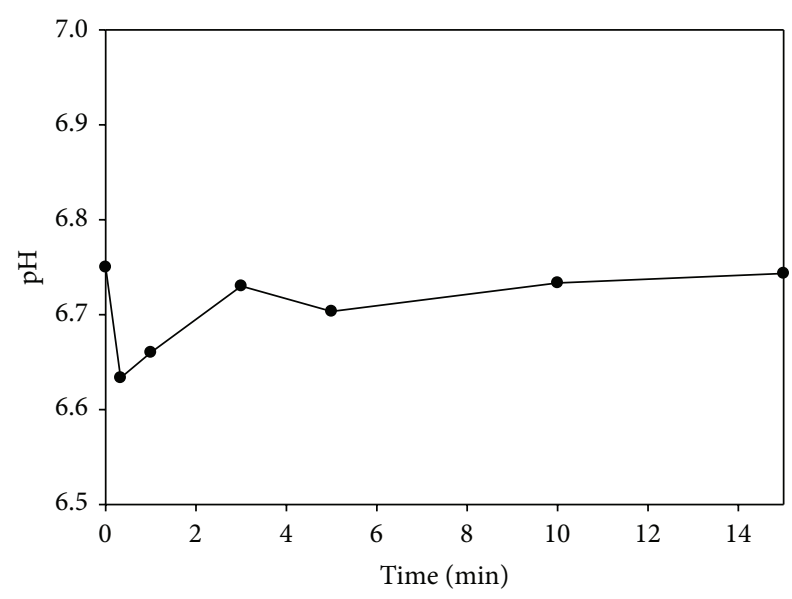

FIgURE 6: Average $\mathrm{pH}$ variation over time for the NFMS hydrated in simulated saliva ( $\mathrm{pH} 6.75)(n=3, \mathrm{SD}<0.01)$.

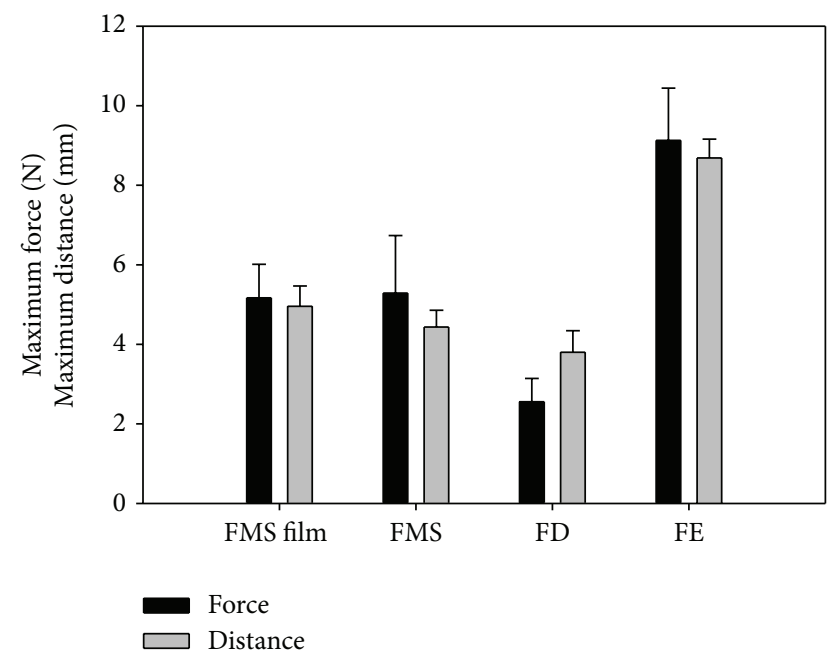

FIgURE 7: Vertical bar chart outlining average maximum force and distance values for the film of the nanofibrous matrix system (NFMS), the complete NFMS, drug-loaded NFMS film (FD) and comparator film containing the same components as the electrospinning solution (FE).

and toughness (Figure 8(a)). Young's modulus of the fiber layer was greater than that of the FE film (Figure 8(e)) but smaller than the other tested samples, suggesting that it was more flexible than the film onto which it was incorporated but less flexible than the FE film. When compared to the FE film, which was prepared using the same components at the same ratios, the fiber layer was found to have a larger Young's modulus and a considerably smaller yield stress, ultimate strength, ultimate strain, and toughness, as well as a smaller elastic region (green portion of nanotensile profile), which may be attributed to the elongating forces experienced by polymer chains during electrospinning [21, 41]. When a polymer is exposed to greater elongating forces, the fibers that are formed will have smaller diameters, which have also been associated with a larger Young's modulus and hence a greater stiffness. It can therefore be deduced that the differences between the tensile properties of the fiber layer and the
FE film are due to polymer chain stretching during fiber formation. The NFMS film revealed slightly larger values than the fiber layer for the various responses determined during nanotensile testing (Figure $8(\mathrm{~b})$ ). This may be due to the presence of the more rigid polymer, HPMC, in the film. The profile for the NFMS revealed two distinct points of fracture-the first one being the point at which the fiber layer fractured and the second where the film layer fractured (Figure 8(c)). The FD film (Figure 8(d)), which is the DPHloaded NFMS film, featured a substantially larger Young's modulus than the NFMS film, suggesting that the presence of DPH in the formulation enhanced the rigidity of the film.

The results of nanotensile testing were in agreement with the extensibility results in the previous section. However, the two tests were performed disparately and with varying sensitivity. The extensibility test utilized a large sample area, imbedded a probe into the sample until fracture, and measured the force-distance relationship, whereas the nanotensile test employed only a small sample area, pulled the sample apart until fracture, and measured the stress-strain relationship, from which various parameters, such as Young's modulus, yield stress, and toughness, could be calculated. While both tests are useful, the nanotensile test was more applicable for this particular formulation due to the method of testing, type of results produced, and the augmented sensitivity of the test.

3.9. Mucoadhesive Properties. The average maximum detachment force (MDF) and work of adhesion (WA) were determined from the peak and AUC, respectively, of the forcedistance profiles generated by mucoadhesive testing. Table 7 outlines the values of MDF and WA for the NFMS film, nanofibrous layer, and the drug-loaded films (FD and FE). The backing film of the NFMS exhibited an adequate MDF and WA. The nanofibrous layer was observed to be somewhat more mucoadhesive than the film; however, due to the rapid disintegration rate of the fibers, the backing film is required to hold the system in place and ensure that the released drug is detained at the buccal mucosa until absorption occurs. The FE film was found to have a considerably larger MDF than the nanofibrous layer of the NFMS. This may be attributed to the rapid disintegration rate of the fibers, resulting in less of the formulation being available in its original form at the point in time when mucoadhesion was measured, as opposed to the slower disintegration rate of the FE film. In comparison to the NFMS film layer, the FD film displayed an exceedingly smaller MDF and WA. From this, it can be deduced that the addition of drug to the film formulation resulted in a reduction in mucoadhesiveness. The disparity between the MDF and WA values of the NFMS backing film and the FE film may be due to the presence of HPMC in the NFMS film formulation. HPMC has poorly flexible chains due to a high glass transition temperature and is therefore poorly mucoadhesive [42], and hence the addition of HPMC to the film formulation will decrease the mucoadhesive strength of the resulting film.

3.10. Disintegration Time of the Optimized NFMS and DrugLoaded Films. The time taken for the NFMS and the FD and FE films to disintegrate was 12.8 seconds, 15.8 seconds, 


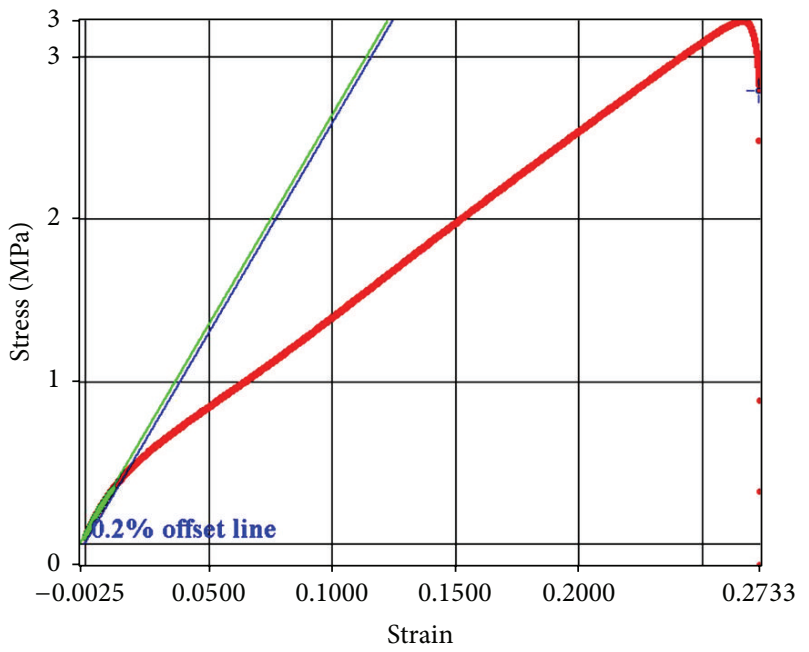

(a)

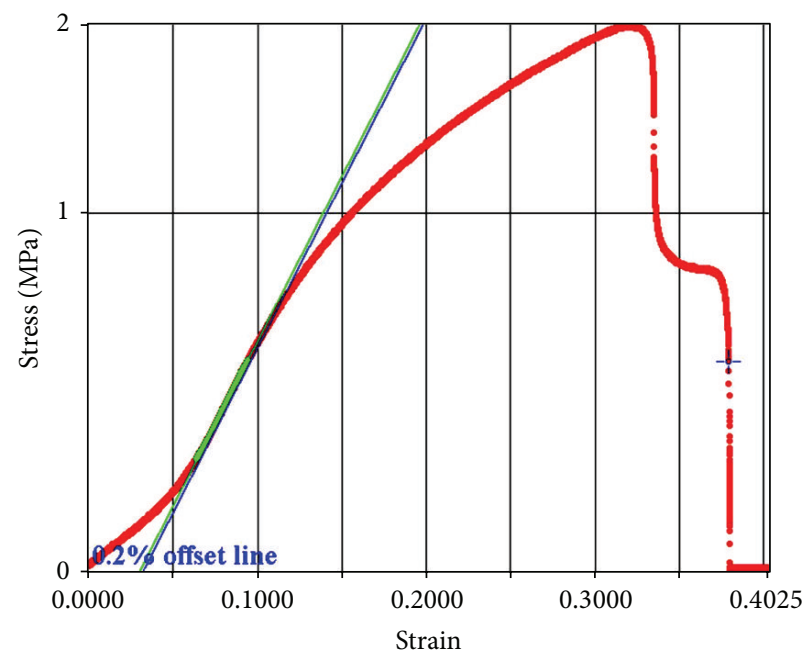

(c)

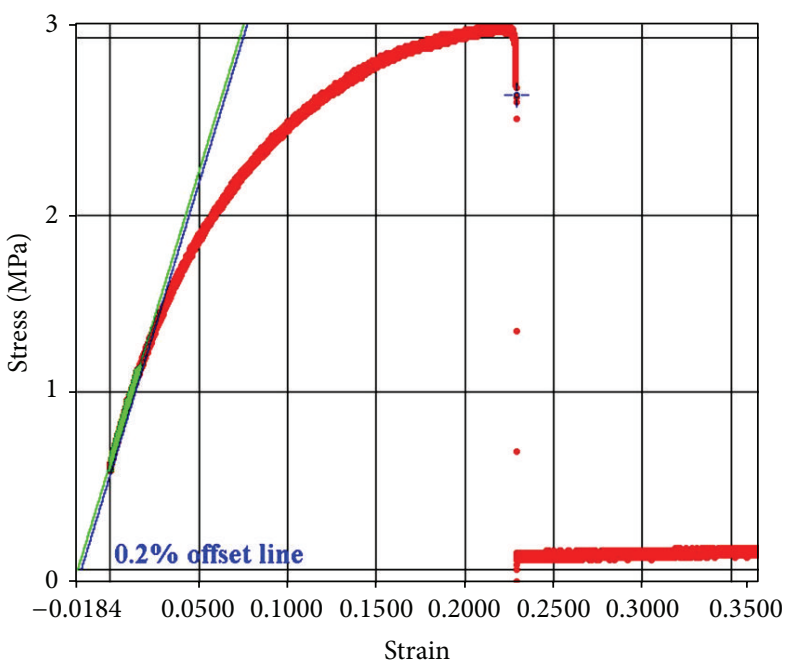

(b)

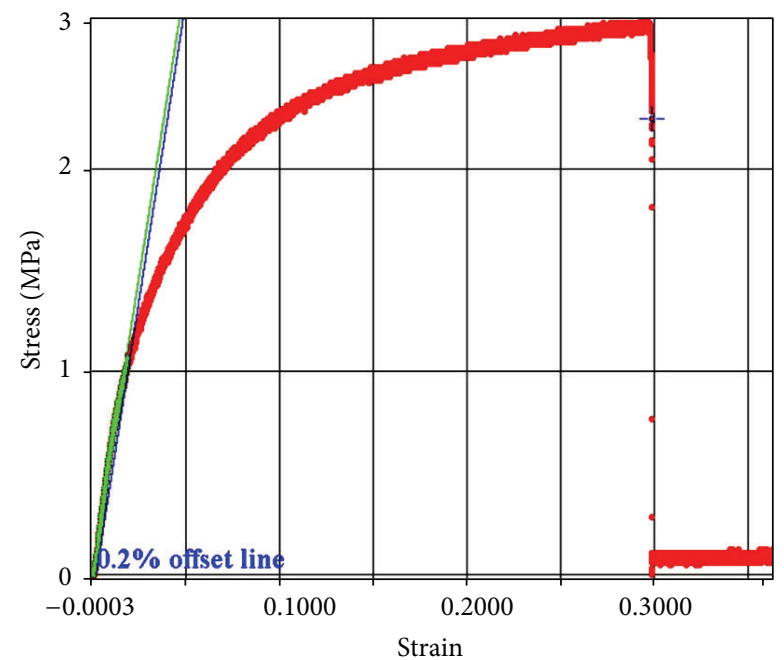

(d)

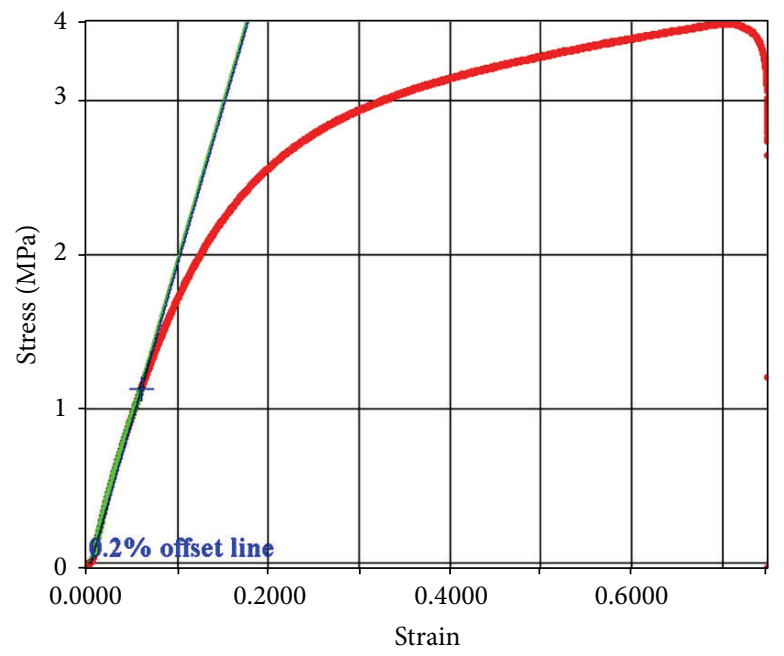

(e)

FIGURE 8: Stress-strain nanotensile profiles of the (a) drug-loaded fiber layer of NFMS, (b) film of NFMS, (c) complete NFMS, (d) FD film (drug-loaded), and (e) FE film (drug-loaded). 
TABLE 7: MDF and WA for the matrix and different films under study.

\begin{tabular}{lcc}
\hline Formulation & MDF & WA \\
\hline NFMS film & 0.2705 & 0.335 \\
NFMS nanofibrous layer & 0.2982 & 0.601 \\
FD & 0.0468 & 0.041 \\
FE & 0.3867 & 0.599 \\
\hline
\end{tabular}

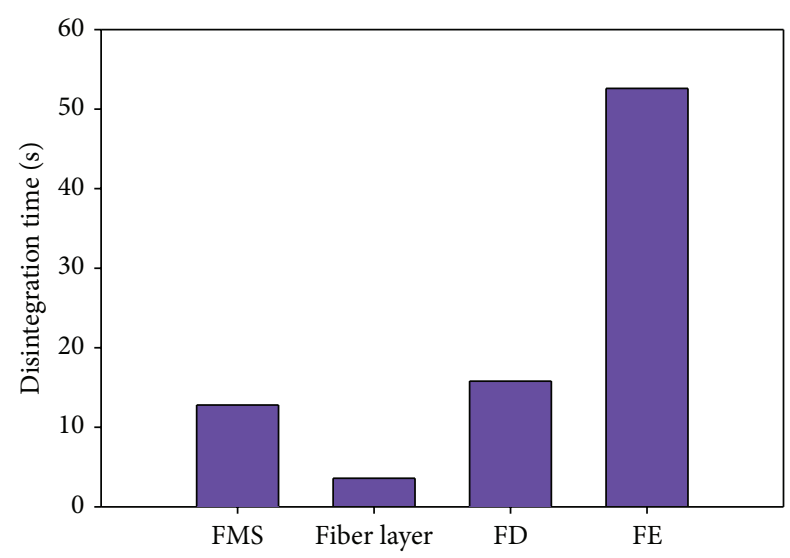

Figure 9: Disintegration times of the nanofibrous matrix system (NFMS), fiber layer of the NFMS, drug-loaded optimized film (FD), and film formed from the same components as the electrospinning solution (FE) $(n=3, \mathrm{SD}<1)$.

and 52.6 seconds, respectively, and is depicted graphically in Figure 9. The DPH-loaded fiber layer of the NFMS took an average of 3.6 seconds to disintegrate, which is considerably shorter than the time taken for the drug-loaded films or the NFMS to disintegrate. This very short time period of disintegration may not suffice or correlate with the optimum time required for the absorption of the released drug through oramucosa and may result in poor bioavailability of the drug due to swallowing of major drug content. In order to keep the drug at the surface of absorption and prevent swallowing, the backing film layer in NFMS should remain intact for a longer period of time than the fiber layer. However, if the film remains intact for too long, it may result in poor mouthfeel and affect patient acceptability. The polymer backing film supports the fiber layer and retains it for an optimum extended period of time, as seen in Figure 9, ensuring maximum drug absorption without compromising the patient compliance.

3.11. Drug Entrapment and In Vitro Drug Release. The average drug entrapment of the NFMS, FD, and FE films was determined as $2.3 \mathrm{mg} \pm 0.44 \mathrm{mg}, 8.8 \mathrm{mg} \pm 0.11 \mathrm{mg}$, and $5.5 \mathrm{mg} \pm$ $0.48 \mathrm{mg}$, respectively. The optimized NFMS exhibited a rapid dissolution rate, with an average of $63 \%$ of the loaded dose releasing in 1 minute and $86 \%$ in 3 minutes. In comparison, the FD and FE films released $27 \%$ and $17 \%$ of the loaded dose in 1 minute and $48 \%$ and $46 \%$ at 3 minutes, respectively. The drug release profiles are depicted in Figure 10(a). It is apparent that the dissolution rate of the NFMS is significantly more rapid than that of either of the drugloaded films, owing to the extremely high surface area of the nanofibrous layer in comparison with films $[8,10]$, which enhances the rate of disintegration and dissolution [14]. Figure 10(b) compares the drug release profiles of the NFMS and the branded comparator product, Sleepeze-PM, the later displaying a relatively rapid drug release, with $31 \%$ and $55 \%$ of the loaded dose releasing after 1 and 3 minutes, respectively. However, the optimized NFMS exhibited a superior drug release profile in a considerably smaller volume of buffer, which makes it preferable to the conventional system on the market in terms of its rapid action.

The area under the curve $\left(\mathrm{AUC}_{\mathrm{D}}\right)$ at 1 minute was calculated forthe NFMS, FD, and FE films and Sleepeze-PM tablets, and it is illustrated in Figure 10(c). The $\mathrm{AUC}_{\mathrm{D}}$ of the NFMS is nearly 3 times greater than that of the FD film and Sleepeze-PM tablets and approximately 5 times greater than the $\mathrm{AUC}_{\mathrm{D}}$ of the FE film. Hence it can be deduced that drug release from the NFMS occurs more rapidly than from any of the tested comparison formulations.

3.12. Ex Vivo Drug Permeation Studies. Ex vivo drug permeation, where conditions are as similar as possible to in vivo circumstances, is a valuable study to conduct in order to determine the expediency of employing a particular drug or drug delivery system for buccal administration [43]. Figure 11(a) depicts the flux profiles of the NFMS, a $2 \mathrm{mg} / \mathrm{mL}$ DPH solution, and the drug-loaded films, FD and FE. The DPH solution exhibited a slightly greater flux than the NFMS, with $79 \%$ and $78 \%$ of the loaded dose permeated at 3 minutes, respectively. The FD and FE films displayed a lower flux than the NFMS, where $74 \%$ and $55 \%$ of the loaded dose had permeated after 3 minutes, respectively. This is in agreement with the in vitro dissolution data. Permeation AUC $\left(\mathrm{AUC}_{\mathrm{P}}\right)$ at 3 minutes was calculated for the tested formulations and plotted as in Figure 11(b). $\mathrm{AUC}_{\mathrm{P}}$ of the $2 \mathrm{mg} / \mathrm{mL}$ DPH solution was slightly greater than that for the NFMS, suggesting that the rate of permeation of drug from solution was only marginally faster than that from the NFMS. The FE film exhibited the smallest $\mathrm{AUC}_{\mathrm{P}}$ value, and the value for the FD film was between that of the NFMS and FE film. The rate of drug permeation from the DPH-loaded films was somewhat slower than that from the NFMS or the drug solution.

The apparent permeability coefficient $\left(P_{\text {app }}\right)$ and steady state flux $\left(J_{s s}\right)$ values were calculated for the tested formulations and are outlined in Table 8 . These values were in accordance with those for $\mathrm{AUC}_{\mathrm{P}}$ of the various formulations, with the FE film exhibiting the smallest $P_{\text {app }}$ and $J_{\text {ss }}$ values and the DPH solution having the largest $P_{\mathrm{app}}$ and $J_{\mathrm{ss}}$ values.

3.13. Molecular Mechanics Assisted Model Building and Energy Refinements. Molecular mechanics energy relationship (MMER), a method for analytico-mathematical representation of potential energy surfaces, was used to provide information about the contributions of valence terms, noncovalent Coulombic terms, and noncovalent van der Waals 


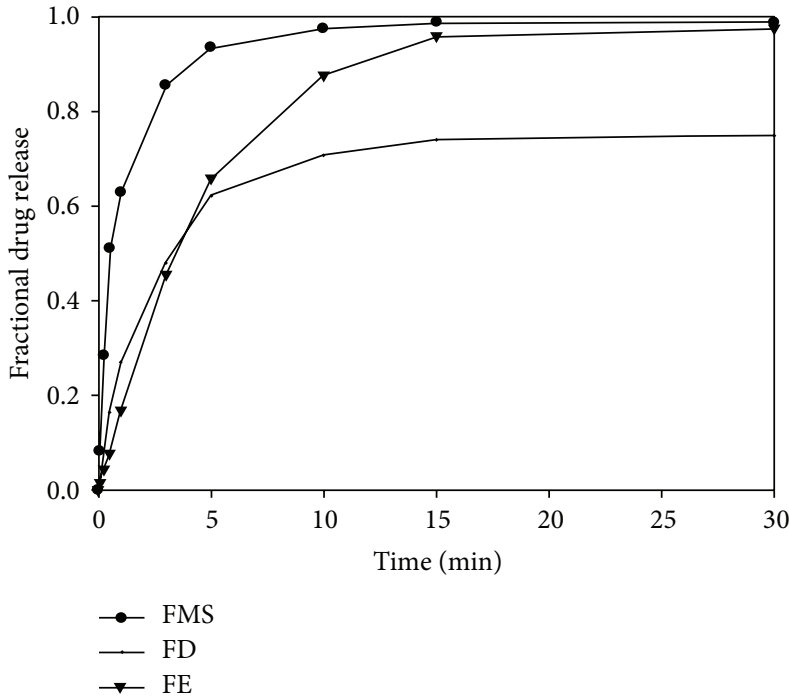

(a)

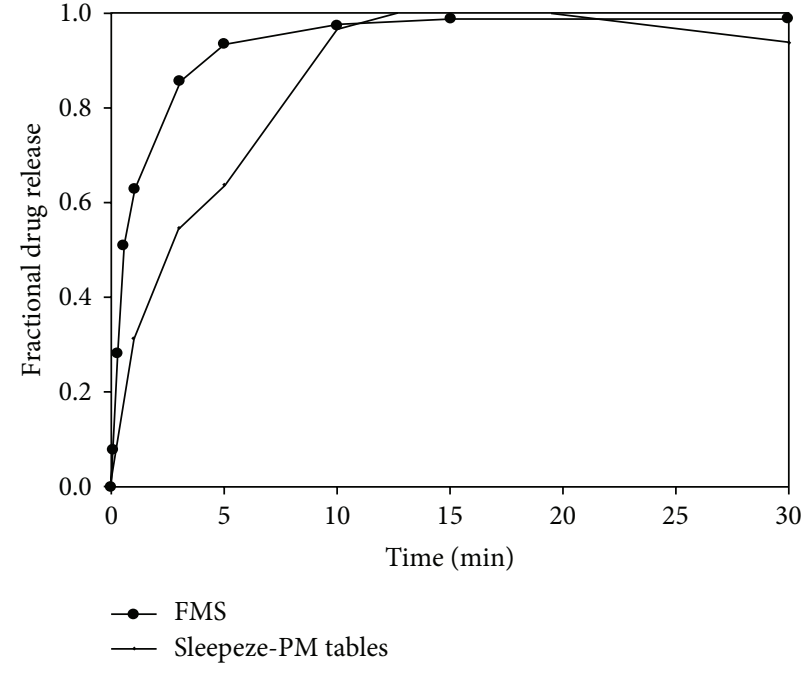

(b)

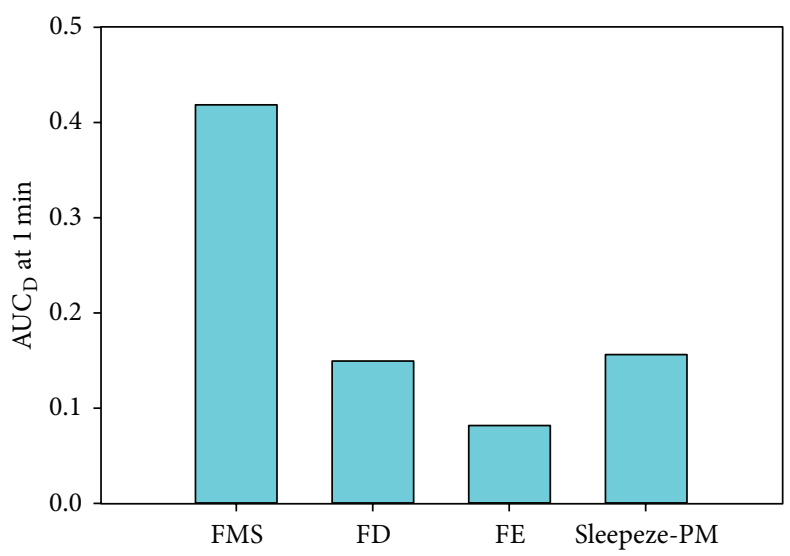

(c)

FIGURE 10: (a) Drug release profiles of the nanofibrous matrix system (NFMS) and the drug-loaded films FD and FE $(n=3$, SD $<0.04)$. (b) Comparative drug release profiles of the nanofibrous matrix system (NFMS) and Sleepeze-PM tablets $\left(n=3, \mathrm{SD}^{\circ}<0.04\right)$ and (c) $\mathrm{AUC}_{\mathrm{D}}$ comparison between the NFMS, comparator DPH-loaded film formulations (FD and FE), and Sleepeze-PM tablets $(n=3$, SD $<0.02)$.

interactions for the plasticizer/polysaccharide/protein morphologies and interactions. The MMER model for the potential/steric energy factors in various molecular complexes can be written as

$$
\begin{array}{r}
E_{\text {molecule } / \text { complex }}=V_{\Sigma}=V_{\mathrm{b}}+V_{\theta}+V_{\varphi}+V_{\mathrm{ij}}+V_{\mathrm{hb}}+V_{\mathrm{el}}, \\
E_{\mathrm{HPMC}}=49.713 V_{\Sigma}=2.089 V_{\mathrm{b}}+18.821+22.360 V_{\varphi} \\
+6.776 V_{\mathrm{ij}}-0.335 V_{\mathrm{hb}}, \\
E_{\mathrm{PVA}}=5.173 V_{\Sigma}=0.615 V_{\mathrm{b}}+1.652 V_{\theta}+0.881 V_{\varphi} \\
+4.895 V_{\mathrm{ij}}-2.871 V_{\mathrm{hb}}, \\
E_{\mathrm{HPMC} / \mathrm{PVA}}=44.321 V_{\Sigma}=2.582 V_{\mathrm{b}}+19.911 V_{\theta} \\
+27.276 V_{\varphi}-2.740 V_{\mathrm{ij}}-2.709 V_{\mathrm{hb}}, \\
{[\Delta E=-10.565 \mathrm{kcal} / \mathrm{moL}]}
\end{array}
$$

$$
\begin{aligned}
E_{\mathrm{MUC}}= & -166.812 V_{\Sigma}=5.474 V_{\mathrm{b}}+70.351 V_{\theta}+55.173 V_{\varphi} \\
& -29.066 V_{\mathrm{ij}}-7.096 V_{\mathrm{hb}}-261.649 V_{\mathrm{el}},
\end{aligned}
$$




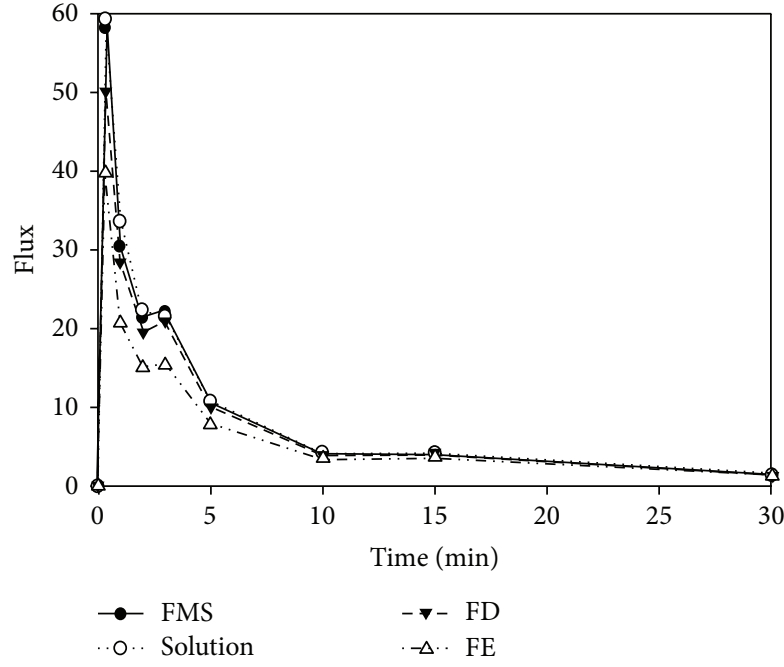

(a)

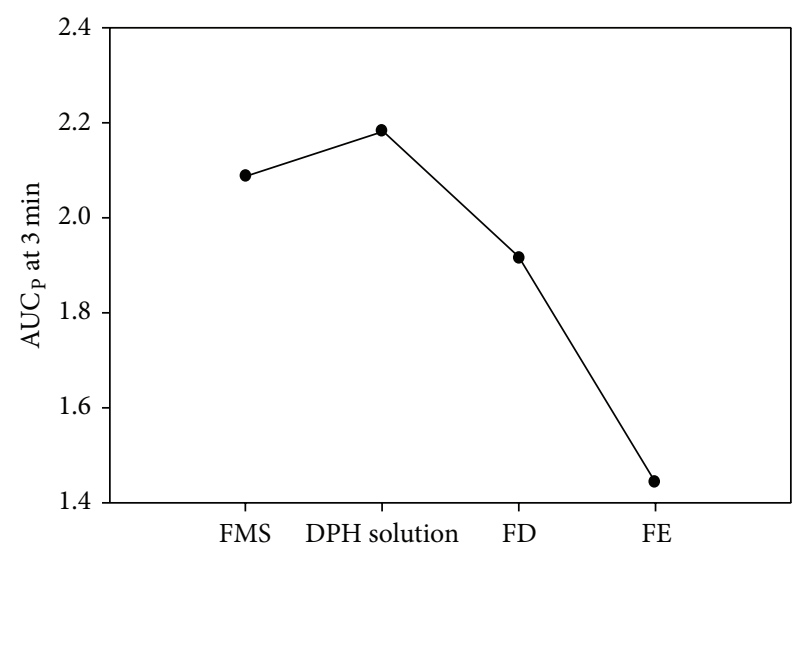

(b)

FIGURE 11: (a) Drug permeation profiles of the matrix system (NFMS), the drug solution, and the drug-loaded film formulation (FD and $\mathrm{FE})\left(n=3, \mathrm{SD}<0.1\right.$ in all cases) and (b) plot depicting $\mathrm{AUC}_{\mathrm{P}}$ at 3 minutes for the nanofibrous matrix system (NFMS), DPH solution, and $\mathrm{DPH}$-loaded film formulation (FD and FE) $(n=3, \mathrm{SD}<0.02$ in all cases).

$$
\begin{aligned}
E_{\mathrm{HPMC} / \mathrm{MUC}}= & -156.127 V_{\Sigma}=6.888 V_{\mathrm{b}}+88.277 V_{\theta} \\
& +84.268 V_{\varphi}-51.281 V_{\mathrm{ij}}-7.555 V_{\mathrm{hb}} \\
& -276.724 V_{\mathrm{el}}, \quad[\Delta E=-39.028 \mathrm{kcal} / \mathrm{moL}],
\end{aligned}
$$

$$
\begin{gathered}
E_{\mathrm{PVA} / \mathrm{MUC}}=-175.667 V_{\Sigma}=6.486 V_{\mathrm{b}}+72.435 V_{\theta}+66.468 V_{\varphi} \\
-48.050 V_{\mathrm{ij}}-9.266 V_{\mathrm{hb}}-263.742 V_{\mathrm{el}}, \\
{[\Delta E=-14.028 \mathrm{kcal} / \mathrm{moL}],}
\end{gathered}
$$

$$
\begin{aligned}
& E_{\mathrm{HPMC} / \mathrm{PVA} / \mathrm{MUC}}=-170.567 V_{\Sigma}=8.098 V_{\mathrm{b}}+91.792 V_{\theta} \\
&+78.881 V_{\varphi}-63.968 V_{\mathrm{ij}} \\
&-9.755 V_{\mathrm{hb}}-275.615 V_{\mathrm{el}}, \\
& {[\Delta E=-58.641 \mathrm{kcal} / \mathrm{moL}], }
\end{aligned}
$$

where $V_{\Sigma}$ is related to total steric energy for an optimized structure, $V_{\mathrm{b}}$ corresponds to bond stretching contributions (reference values were assigned to all of structure's bond lengths), $V_{\theta}$ denotes bond angle contributions (reference values were assigned to all of structure's bond angles), $V_{\varphi}$ represents torsional contribution arising from deviations from optimum dihedral angles, $V_{\mathrm{ij}}$ incorporates van der Waals interactions due to nonbonded interatomic distances, $V_{\mathrm{hb}}$ symbolizes hydrogen-bond energy function and $V_{\mathrm{el}}$ stands for electrostatic energy. In addition, the total potential energy deviation, $\Delta E_{\text {total }}$, was calculated as the difference between the total potential energy of the complex system and the sum of the potential energies of isolated individual molecules as follows:

$$
\Delta E_{\operatorname{Total}(A / B)}=E_{\operatorname{Total}(A / B)}-\left(E_{\operatorname{Total}(A)}+E_{\operatorname{Total}(B)}\right) .
$$

TABLE 8: Calculated apparent permeability coefficient $\left(P_{\text {app }}\right)$ and steady state flux $\left(J_{\text {ss }}\right)$ values for the formulations under study.

\begin{tabular}{lcc}
\hline Formulation & $P_{\text {app }}$ & $J_{\text {ss }}$ \\
\hline NFMS & $4.9 \times 10^{-4}$ & 5.88 \\
DPH solution & $5.0 \times 10^{-4}$ & 5.95 \\
FD & $4.7 \times 10^{-4}$ & 5.60 \\
FE & $3.4 \times 10^{-4}$ & 4.11 \\
\hline
\end{tabular}

The molecular stability can then be estimated by comparing the total potential energies of the isolated and complexed systems. If the total potential energy of complex is smaller than the sum of the potential energies of isolated individual molecules in the same conformation, the complexed form is more stable and its formation is favoured [44].

3.13.1. Energy Computations for Polymer/Plasticizer Complexes Using Atomistic Simulations. The molecular confirmations obtained from the simulation of HPMC, PVA, and glycerol (GLY) are represented by Figure 12, Table 9, and (4)-(9). The effects of blending PVA with HPMC (HPMC/PVA) and glycerol with HPMC (HPMC/GLY) and blending all three altogether are elucidated herein. It is evident from the energy computations that all the three complexes are well stabilized due to -ve $\Delta E((4)-(9))$. HPMC contains interactive oxygen containing groups in the form of $-\mathrm{C}-\mathrm{O}-\mathrm{C}-$ (both in the ring and the methyl side chain) and hydroxyl group for possible association with glycerine molecules. Specifically, the oxofunctionalities of HPMC and the hydroxyl functionality of glycerine may interact with directional orientation acting at adequately short distances (Figure 12(a)), H-bonding, and van der Waals attractive interactions resulting in energy minimization of $28.318 \mathrm{kcal} / \mathrm{mol}$. Similarly, in case of HPMC/PVA, the hydroxyl group of PVA interacted with $-\mathrm{C}-\mathrm{O}-\mathrm{C}-$ moiety 


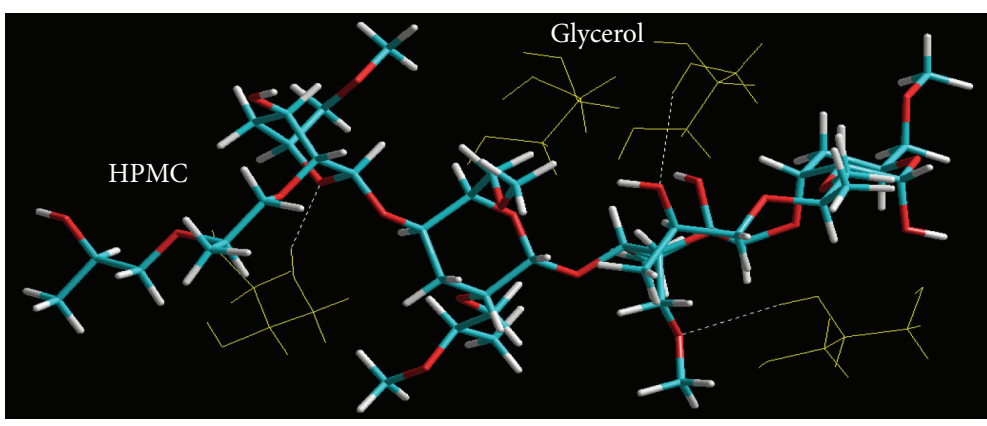

(a)

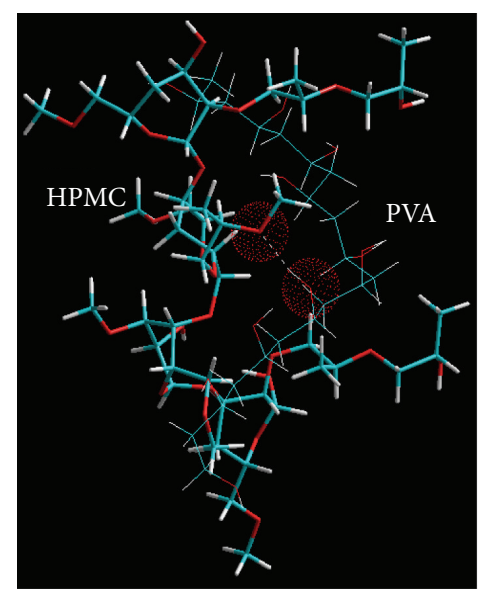

(b)

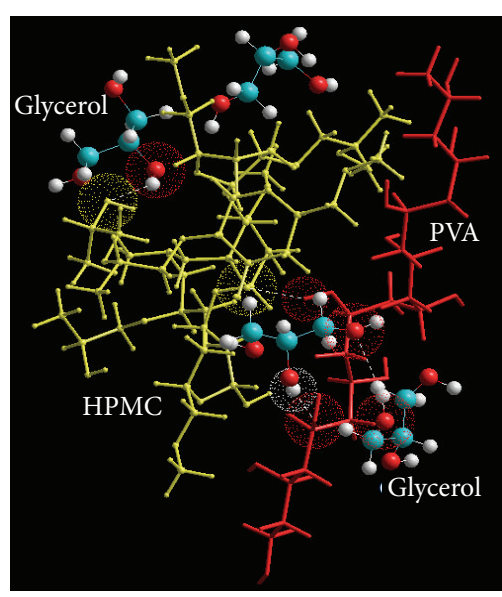

(c)

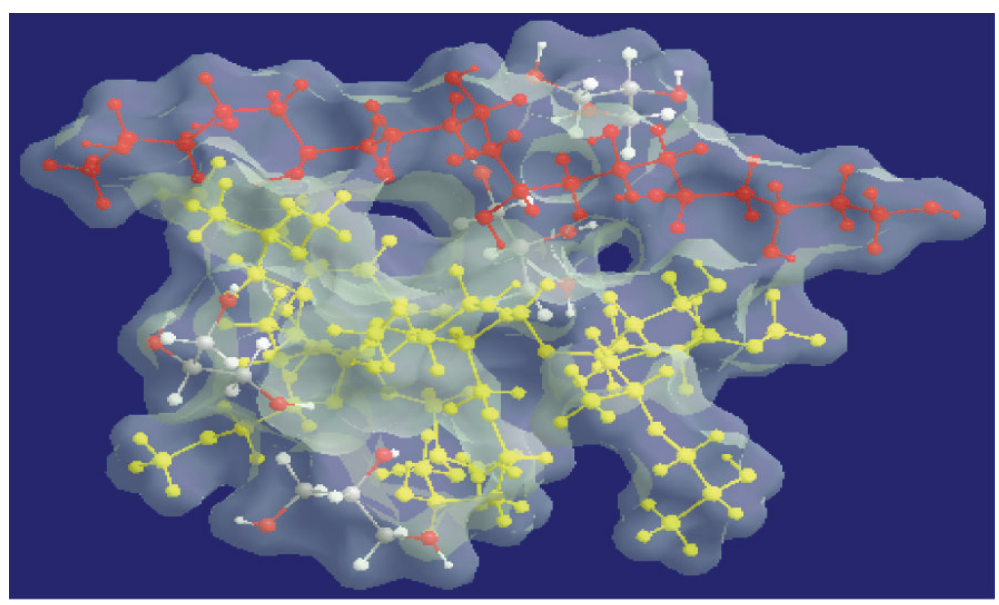

(d)

FIGURE 12: Visualization of geometrical preferences of (a) HPMC/glycerol complex, (b) HPMC/PVA complex, and (c) HPMC/PVA/Glycerol complex and (d) connolly molecular electrostatic potential surfaces in translucent display mode showcasing the trimolecular complex after molecular simulation. The atoms involved in $\mathrm{H}$-bonding are emphasized by space filling model (dots). Color codes for elements are $\mathrm{C}$ (cyan), $\mathrm{O}$ (red), and $\mathrm{H}$ (white).

TABLE 9: Molecular mechanics evaluation of the surface-to-volume ratio and density of pure polymers and blends.

\begin{tabular}{lccccc}
\hline Molecular complex & Surface area $\left(\AA^{2}\right)$ & Volume $\left(\AA^{3}\right)$ & SVR $^{\#}$ & Mass $(\mathrm{amu})$ & Density $\left(\mathrm{amu} / \AA^{3}\right)$ \\
\hline HPMC & 1374.70 & 2655.35 & 0.5177 & 993.15 & 0.3740 \\
PVA & 785.80 & 1327.24 & 0.5920 & 442.55 & 0.3334 \\
Glycerol & 982.04 & 1333.36 & 0.7365 & 368.36 & 0.2762 \\
HPMC/PVA & 1548.78 & 3476.73 & 0.4454 & 1435.69 & 0.4129 \\
HPMC/GLY & 1436.69 & 3247.83 & 0.4423 & 1361.53 & 0.4192 \\
HPMC/PVA/GLY & 1624.86 & 4052.57 & 0.4009 & 1804.07 & 0.4452 \\
\hline
\end{tabular}

${ }^{\#}$ SVR: surface-to-volume ratio.

of HPMC with an energy minimization of $10.565 \mathrm{kcal} / \mathrm{moL}$ (Figure 12(b)). Furthermore, we carried out the full simulation of HPMC/PVA/GLY to see whether the individual blend interactions still persist or not. It is evident from Figure 12 that apart from all the previous $\mathrm{H}$-bonding interactions, PVA also interacted with GLY forming a GLY-HPMC-GLY-PVAGLY complex (Figure 12(c)) resulting in an even higher stabilization of potential energy $(\Delta E=-42.515 \mathrm{kcal} / \mathrm{moL})$. In all three blend simulations, the nonbonding London dispersion hydrophobic forces dominated the overall contribution from all the energy terms, further explaining the vigorous geometrical conformational requirements desirable for the networks between these polymer/plasticizer fragments (Figure 12(d)).

In addition, the molecular attributes in terms of surfaceto-volume ratio (SVR) and final density corroborated with the above findings with HPMC/PVA/GLY having lowest SVR followed by HPMC/GLY, and HPMC/PVA (Table 9). The lower the surface-to-volume ratio, the more stable 


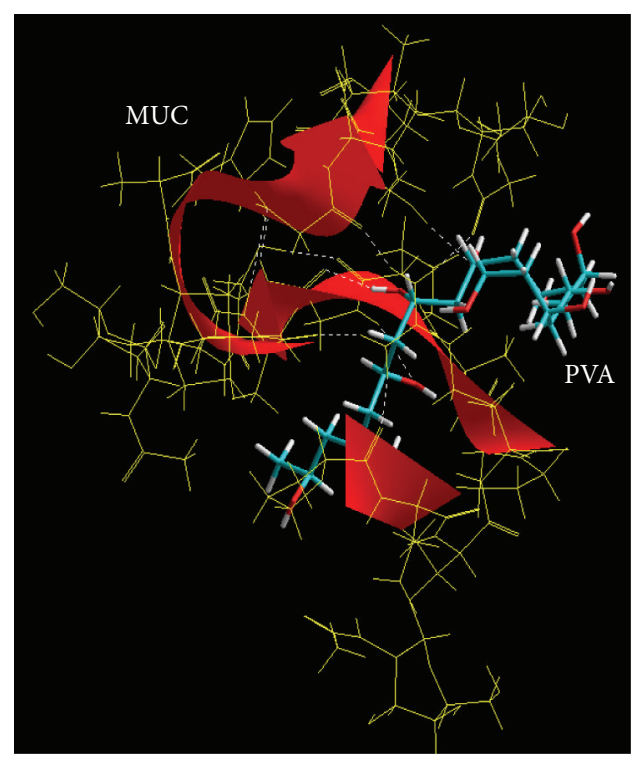

(a)

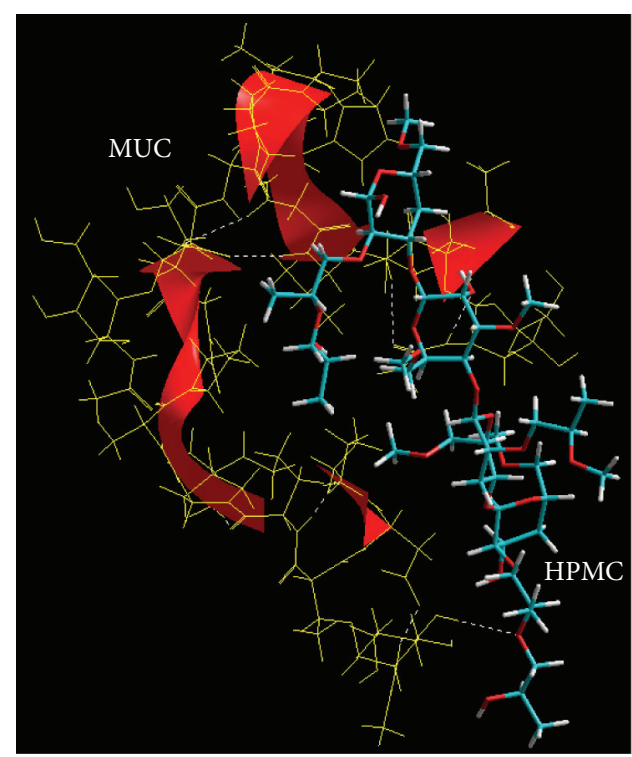

(b)

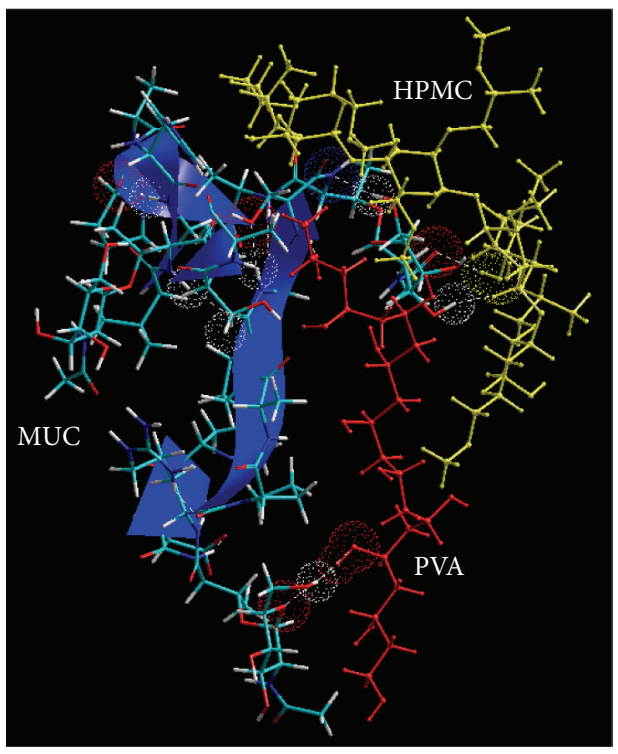

(c)

FIGURE 13: Visualization of geometrical preferences of (a) PVA/MUC complex, (b) HPMC/MUC complex, and (c) HPMC/PVA/MUCl complex after molecular simulation. The atoms involved in $\mathrm{H}$-bonding are emphasized by space filling model (dots). Color codes for elements: $\mathrm{C}$ (cyan), $\mathrm{O}$ (red), $\mathrm{N}$ (blue) and $\mathrm{H}$ (white).

the structure. In this study, initial models were developed employing a derivative approach based on average-density function of the pure systems. Considering the polymerpolymer/polymer-plasticizer system, a substantial increase in the network density was detected as compared to the average of the component individual molecules, with density values ranging from 0.4129 through 0.4192 to $0.4452 \mathrm{amu} / \AA^{3}$ for $\mathrm{HPMC} / \mathrm{PVA}$, HPMC/GLY and $\mathrm{HPMC} / \mathrm{PVA} / \mathrm{GLY}$, respectively. Interestingly, these density increments are in corroboration with the appearance of specific interchain networking forming a miscible interphase in between the three molecules [45]. Thus we conclude that the energy stabilization, low SVR, and high density lead to highly efficient plasticization of the HPMC/PVA backing film by glycerol. The observations so obtained were in accordance with previously reported results by Sakellariou et al., 1993 where the plasticizer's efficiency was defined in relation to the tendency of the polymer-plasticizer set to form polar as well as hydrogen-bonding interactions [46].

3.13.2. Prediction of Mucoadhesive Potential of the Backing Layer. The bioadhesive or mucoadhesive potential of the NFMS was determined by measuring the detailed chemical interfaces between the individual polymers (HPMC and 
PVA) or polymeric matrix (HPMC/PVA) and the glycosylated oromucopeptide analogue after geometrical optimization using energy minimizations. HPMC and PVA are known to be mucoadhesive polymers and may impart bioadhesion to the drug delivery system [47].

As per the energy consideration, a collective phenomenon comprising van der Waals forces, electrostatic interactions, and $\mathrm{H}$-bonding in the form of nonbonding interactions was reported ((4), (5), and (10)-(13)). This contributed to a stress transduction necessitating the establishment of connectivity between chemically conformed regions via interactive surface generation. Interestingly, the inherent binding energies of the polymer matrices with MUC were quite high ranging from -14.028 through -39.028 to $-58.641 \mathrm{kcal} / \mathrm{moL}$ in case of PVA/MUC, HMPC/MUC, and HPMC/PVA/MUC confirming the significant interactions among the polymer entities and the oromucopeptide (Figure 13 and Table 9). The minimized energy increased significantly after introducing both the polymers together in the MUC-polymer system leading to a comparatively stabilized conformation. Additionally, the $\mathrm{H}$-bonds formed between the polymer matrix and the MUC were increased in case of trimolecular system (Figure 13). A deeper inspection revealed the existence of hydrophobic interactions in the form of methyl groups (from mucopeptide residues) networking with oxofunctionalities of the constituent polymers (Figure 13).

The experimental mucoadhesion studies can be correlated to these in silico findings. As explained earlier in the paper, the mucoadhesion due to hydrophilic polymers is usually accompanied by a "region of maximum" where it is dependent on the concentration of the polymer, such as HPMC in the present case. The contour plot depicted an initial increase in mucoadhesion with increase in the amount of polymers up to the intermediate levels and decreases thereafter. The possible explanation to this is that the HPMC/PVA backing film may readily absorb water while in contact with hydrated mucous membrane leading to swelling of the polymer matrix and may progressively become rubbery because of extensive uncoiling of polymeric chains. Furthermore, this may result in an increase in the mobility of the polymer fragments producing a wide-spread adhesive surface which may thus present with maximum contact area for mucosa to interact and may additionally provide flexibility to the polymer chains for mucosal interpenetration [48]. On contrary, a further increase in the amount of these hydrophilic polymers may render the network structure too dense and less flexible (due to high glass transition temperature as described in mucoadhesion section) to hold the tethered mucous chains thereby decreasing the mucoadhesion [48]. Glycerol may further enhance the mucoadhesion by providing a stabilized and flexible system as postulated in the polymer/plasticizer complexes and also by providing additional hydroxyl bonds to form $\mathrm{H}$-bonds with the mucopeptide.

\section{Conclusions}

Mucoadhesive, drug-loaded electrospun fibers were incorporated directly onto polymeric backing films of PVA and HPMC which were successfully prepared and optimized according to a 3-level 3-factor Box-Behnken experimental design. The effects of the independent variables on the dependent response variables were analyzed, and an optimized formulation was mathematically produced. The physicochemical and physicomechanical characteristics of the optimized NFMS were assessed. The FTIR analysis elucidated no significant chemical interactions occurring between drug, polymer, and excipients during the process of formulation preparation. The complete NFMS exhibited rapid and optimum disintegration time. Although the disintegration and drug release of the fiber matrix alone was high enough, the backing film holds the system in place for an optimum time length ensuring the retention of released drug at buccal mucosa until the absorption occurs. The optimized NFMS thus displayed rapid disintegration and drug release with good mucoadhesion, oramucosal retention, flexibility and minimal mucosal irritation due to $\mathrm{pH}$ variation. The NFMS may therefore be deemed suitable for rapid oramucosal drug delivery. Furthermore, molecular mechanics technique afforded unique understanding on the miscibility profiling and mucoadhesive properties of specific polymer/plasticizer and polymer/mucopeptide complexes, respectively.

\section{Conflict of Interests}

The authors declare that they have no conflict of interests.

\section{Acknowledgments}

This research was funded by the National Research Foundation (NRF) and Technology Innovation Agency (TIA) of South Africa.

\section{References}

[1] J. Doshi and D. H. Reneker, "Electrospinning process and applications of electrospun fibers," Journal of Electrostatics, vol. 35, no. 2-3, pp. 151-160, 1995.

[2] D. Liang, B. S. Hsiao, and B. Chu, "Functional electrospun nanofibrous scaffolds for biomedical applications," Advanced Drug Delivery Reviews, vol. 59, no. 14, pp. 1392-1412, 2007.

[3] T. J. Sill and H. A. von Recum, "Electrospinning: applications in drug delivery and tissue engineering," Biomaterials, vol. 29, no. 13, pp. 1989-2006, 2008.

[4] J. M. Deitzel, J. Kleinmeyer, D. Harris, and N. C. B. Tan, “The effect of processing variables on the morphology of electrospun nanofibers and textiles," Polymer, vol. 42, no. 1, pp. 261-272, 2001.

[5] M. G. McKee, G. L. Wilkes, R. H. Colby, and T. E. Long, "Correlations of solution rheology with electrospun fiber formation of linear and branched polyesters," Macromolecules, vol. 37, no. 5, pp. 1760-1767, 2004.

[6] S. L. Shenoy, W. D. Bates, H. L. Frisch, and G. E. Wnek, "Role of chain entanglements on fiber formation during electrospinning of polymer solutions: good solvent, non-specific polymerpolymer interaction limit," Polymer, vol. 46, no. 10, pp. 33723384, 2005.

[7] A. Frenot and I. S. Chronakis, "Polymer nanofibers assembled by electrospinning," Current Opinion in Colloid and Interface Science, vol. 8, no. 1-2, pp. 64-75, 2003. 
[8] D. H. Reneker and A. L. Yarin, "Electrospinning jets and polymer nanofibers," Polymer, vol. 49, no. 10, pp. 2387-2425, 2008.

[9] X. Zong, K. Kim, D. Fang, S. Ran, B. S. Hsiao, and B. Chu, "Structure and process relationship of electrospun bioabsorbable nanofiber membranes," Polymer, vol. 43, no. 16, pp. 44034412, 2002.

[10] S. Agarwal, J. H. Wendorff, and A. Greiner, "Use of electrospinning technique for biomedical applications," Polymer, vol. 49, no. 26, pp. 5603-5621, 2008.

[11] L. Bruner and St. Tolloczko, "Über die Auflösungsgeschwindigkeit fester Körper," Zeitschrift für Anorganische Chemie, vol. 28, no. 1, pp. 314-330, 1901.

[12] E. Sjokvist and C. Nystrom, "Physicochemical aspects of drug release. XI. Tableting properties of solid dispersions, using xylitol as carrier material," International Journal of Pharmaceutics, vol. 67, no. 2, pp. 139-153, 1991.

[13] G. Verreck, I. Chun, J. Peeters, J. Rosenblatt, and M. E. Brewster, "Preparation and characterization of nanofibers containing amorphous drug dispersions generated by electrostatic spinning," Pharmaceutical Research, vol. 20, no. 5, pp. 810-817, 2003.

[14] A. Dokoumetzidis and P. Macheras, "A century of dissolution research: from Noyes and Whitney to the biopharmaceutics classification system," International Journal of Pharmaceutics, vol. 321, no. 1-2, pp. 1-11, 2006.

[15] G. Ponchel, "Formulation of oral mucosal drug delivery systems for the systemic delivery of bioactive materials," Advanced Drug Delivery Reviews, vol. 13, no. 1-2, pp. 75-87, 1994.

[16] S. Rossi, G. Sandri, and C. M. Caramella, "Buccal drug delivery: a challenge already won?" Drug Discovery Today: Technologies, vol. 2, no. 1, pp. 59-65, 2005.

[17] M. J. Rathbone, B. K. Drummond, and I. G. Tucker, “The oral cavity as a site for systemic drug delivery," Advanced Drug Delivery Reviews, vol. 13, no. 1-2, pp. 1-22, 1994.

[18] J. Abrams, "New nitrate delivery systems: buccal nitroglycerin," The American Heart Journal, vol. 105, no. 5, pp. 848-854, 1983.

[19] O. A. Scholz, A. Wolff, A. Schumacher et al., "Drug delivery from the oral cavity: focus on a novel mechatronic delivery device," Drug Discovery Today, vol. 13, no. 5-6, pp. 247-253, 2008.

[20] D. M. Simpson, J. Messina, F. Xie, and M. Hale, "Fentanyl buccal tablet for the relief of breakthrough pain in opioid-tolerant adult patients with chronic neuropathic pain: a multicenter, randomized, double-blind, placebo-controlled study," Clinical Therapeutics, vol. 29, no. 4, pp. 588-601, 2007.

[21] A. Baji, Y. W. Mai, S. C. Wong, M. Abtahi, and P. Chen, "Electrospinning of polymer nanofibers: effects on oriented morphology, structures and tensile properties," Composites Science and Technology, vol. 70, no. 5, pp. 703-718, 2010.

[22] E. P. S. Tan and C. T. Lim, "Mechanical characterization of nanofibers-a review," Composites Science and Technology, vol. 66, no. 9, pp. 1102-1111, 2006.

[23] E. P. S. Tan, S. Y. Ng, and C. T. Lim, "Tensile testing of a single ultrafine polymeric fiber," Biomaterials, vol. 26, no. 13, pp. 14531456, 2005.

[24] T. Coviello, F. Alhaique, C. Parisi, P. Matricardi, G. Bocchinfuso, and M. Grassi, "A new polysaccharidic gel matrix for drug delivery: preparation and mechanical properties," Journal of Controlled Release, vol. 102, no. 3, pp. 643-656, 2005.

[25] S. N. R. Adhikari, B. S. Nayak, A. K. Nayak, and B. Mohanty, "Formulation and evaluation of buccal patches for delivery of atenolol," AAPS PharmSciTech, vol. 11, no. 3, pp. 1038-1044, 2010.
[26] M. A. Zaman, G. P. Martin, and G. D. Rees, "Mucoadhesion, hydration and rheological properties of non-aqueous delivery systems (NADS) for the oral cavity," Journal of Dentistry, vol. 36, no. 5, pp. 351-359, 2008.

[27] G. P. Andrews, T. P. Laverty, and D. S. Jones, "Mucoadhesive polymeric platforms for controlled drug delivery," European Journal of Pharmaceutics and Biopharmaceutics, vol. 71, no. 3, pp. 505-518, 2009.

[28] L. Perioli, V. Ambrogi, F. Angelici et al., "Development of mucoadhesive patches for buccal administration of ibuprofen," Journal of Controlled Release, vol. 99, no. 1, pp. 73-82, 2004.

[29] B. Singh, R. Kumar, and N. Ahuja, "Optimizing drug delivery systems using systematic "design of experiments"-part I: fundamental aspects," Critical Reviews in Therapeutic Drug Carrier Systems, vol. 22, no. 1, pp. 27-105, 2005.

[30] S. L. C. Ferreira, R. E. Bruns, H. S. Ferreira et al., "Box-Behnken design: an alternative for the optimization of analytical methods," Analytica Chimica Acta, vol. 597, no. 2, pp. 179-186, 2007.

[31] G. E. P. Box and D. W. Behnken, "Some new three level designs for the study of quantitative variables," Technometrics, vol. 2, no. 4, pp. 455-475, 1960.

[32] S. Chopra, S. K. Motwani, Z. Iqbal, S. Talegaonkar, F. J. Ahmad, and R. K. Khar, "Optimisation of polyherbal gels for vaginal drug delivery by Box-Behnken statistical design," European Journal of Pharmaceutics and Biopharmaceutics, vol. 67, no. 1, pp. 120-131, 2007.

[33] V. M. Patel, B. G. Prajapati, and M. M. Patel, "Formulation, evaluation, and comparison of bilayered and multilayered mucoadhesive buccal devices of propranolol hydrochloride," AAPS PharmSciTech, vol. 8, no. 1, pp. E147-E154, 2007.

[34] B. Sibeko, V. Pillay, Y. E. Choonara et al., "Computational molecular modeling and structural rationalization for the design of a drug-loaded PLLA/PVA biopolymeric membrane," Biomedical Materials, vol. 4, no. 1, Article ID 015014, 2009.

[35] S. Azarmi, W. Roa, and R. Löbenberg, "Current perspectives in dissolution testing of conventional and novel dosage forms," International Journal of Pharmaceutics, vol. 328, no. 1, pp. 12-21, 2007.

[36] A. Figueiras, J. Hombach, F. Veiga, and A. Bernkop-Schnürch, "In vitro evaluation of natural and methylated cyclodextrins as buccal permeation enhancing system for omeprazole delivery," European Journal of Pharmaceutics and Biopharmaceutics, vol. 71, no. 2, pp. 339-345, 2009.

[37] P. Kumar, V. Pillay, Y. E. Choonara, G. Modi, D. Naidoo, and L. C. du Toit, "In silico theoretical molecular modeling for Alzheimer's disease: the nicotine-curcumin paradigm in neuroprotection and neurotherapy," International Journal of Molecular Sciences, vol. 12, no. 1, pp. 694-724, 2011.

[38] M. E. Malone, I. A. M. Appelqvist, and I. T. Norton, "Oral behaviour of food hydrocolloids and emulsions-part 1: lubrication and deposition considerations," Food Hydrocolloids, vol. 17, no. 6, pp. 763-773, 2003.

[39] S. Ramakrishna, K. Fujihara, W. E. Teo, T. C. Lim, and Z. Ma, An Introduction to Electrospinning and Nanofibers, World Scientific, London, UK, 2005.

[40] P. Bottenberg, R. Cleymaet, C. de Muynck et al., "Development and testing of bioadhesive, fluoride-containing slow-release tablets for oral use," Journal of Pharmacy and Pharmacology, vol. 43, no. 7, pp. 457-464, 1991.

[41] J. W. Lu, Z. P. Zhang, X. Z. Ren, Y. Z. Chen, J. Yu, and Z. X. Guo, "High-elongation fiber mats by electrospinning of polyoxymethylene," Macromolecules, vol. 41, no. 11, pp. 3762-3764, 2008. 
[42] E. Karavas, E. Georgarakis, and D. Bikiaris, "Application of PVP/HPMC miscible blends with enhanced mucoadhesive properties for adjusting drug release in predictable pulsatile chronotherapeutics," European Journal of Pharmaceutics and Biopharmaceutics, vol. 64, no. 1, pp. 115-126, 2006.

[43] Y. Sudhakar, K. Kuotsu, and A. K. Bandyopadhyay, "Buccal bioadhesive drug delivery-a promising option for orally less efficient drugs," Journal of Controlled Release, vol. 114, no. 1, pp. 15-40, 2006.

[44] B. Y. Yu, J. W. Chung, and S. Y. Kwak, "Reduced migration from flexible poly(vinyl chloride) of a plasticizer containing $\beta$ cyclodextrin derivative," Environmental Science and Technology, vol. 42 , no. 19, pp. 7522-7527, 2008.

[45] H. Abou-Rachid, L. Lussier, S. Ringuette, X. Lafleur-Lambert, M. Jaidann, and J. Brisson, "On the correlation between miscibility and solubility properties of energetic plasticizers/polymer blends: modeling and simulation studies," Propellants, Explosives, Pyrotechnics, vol. 33, no. 4, pp. 301-310, 2008.

[46] P. Sakellariou, A. Hassan, and R. C. Rowe, "Plasticization of aqueous poly (vinyl alcohol) and hydroxypropyl methylcellulose with polyethylene glycols and glycerol," European Polymer Journal, vol. 29, no. 7, pp. 937-943, 1993.

[47] N. K. Mongia, K. S. Anseth, and N. A. Peppas, "Mucoadhesive poly(vinyl alcohol) hydrogels produced by freezing/thawing processes: applications in the development of wound healing systems," Journal of Biomaterials Science, Polymer Edition, vol. 7, no. 12, pp. 1055-1064, 1996.

[48] P. Kumar and M. Bhatia, "Functionalization of chitosan/methylcellulose interpenetrating polymer network microspheres for gastroretentive application using central composite design," PDA Journal of Pharmaceutical Science and Technology, vol. 64, no. 6, pp. 497-506, 2010. 

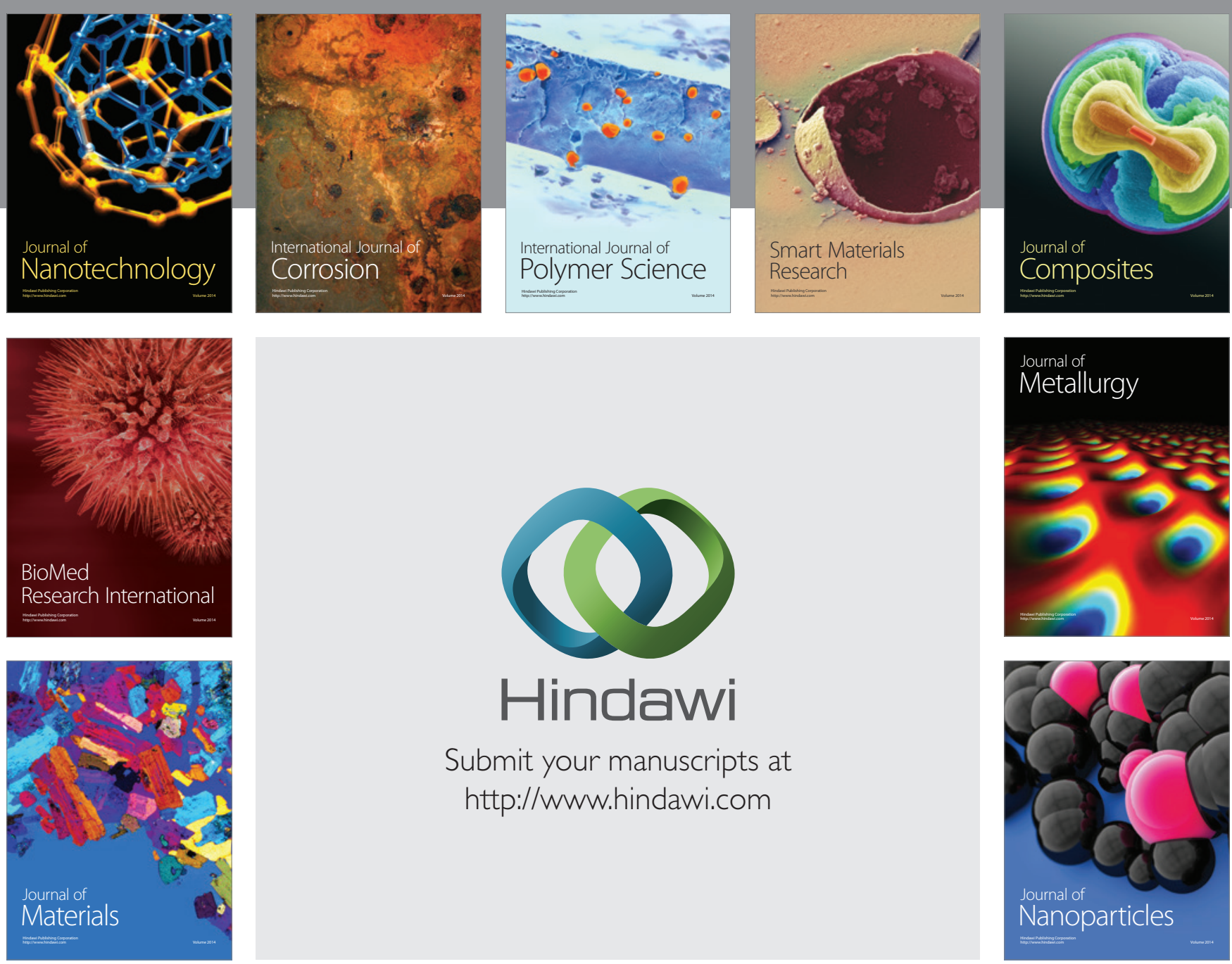

Submit your manuscripts at http://www.hindawi.com
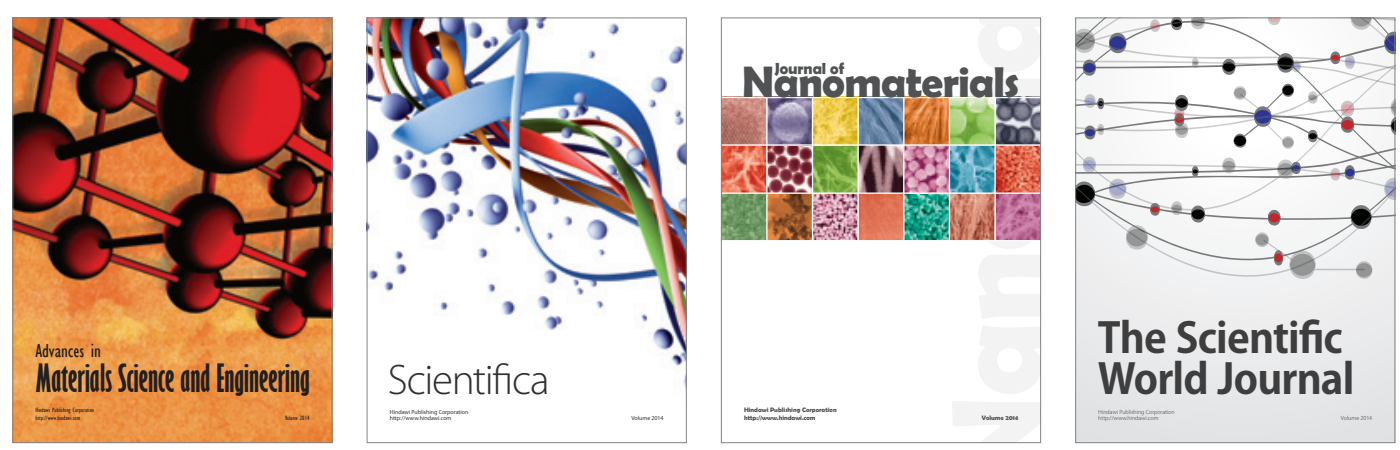

\section{The Scientific World Journal}
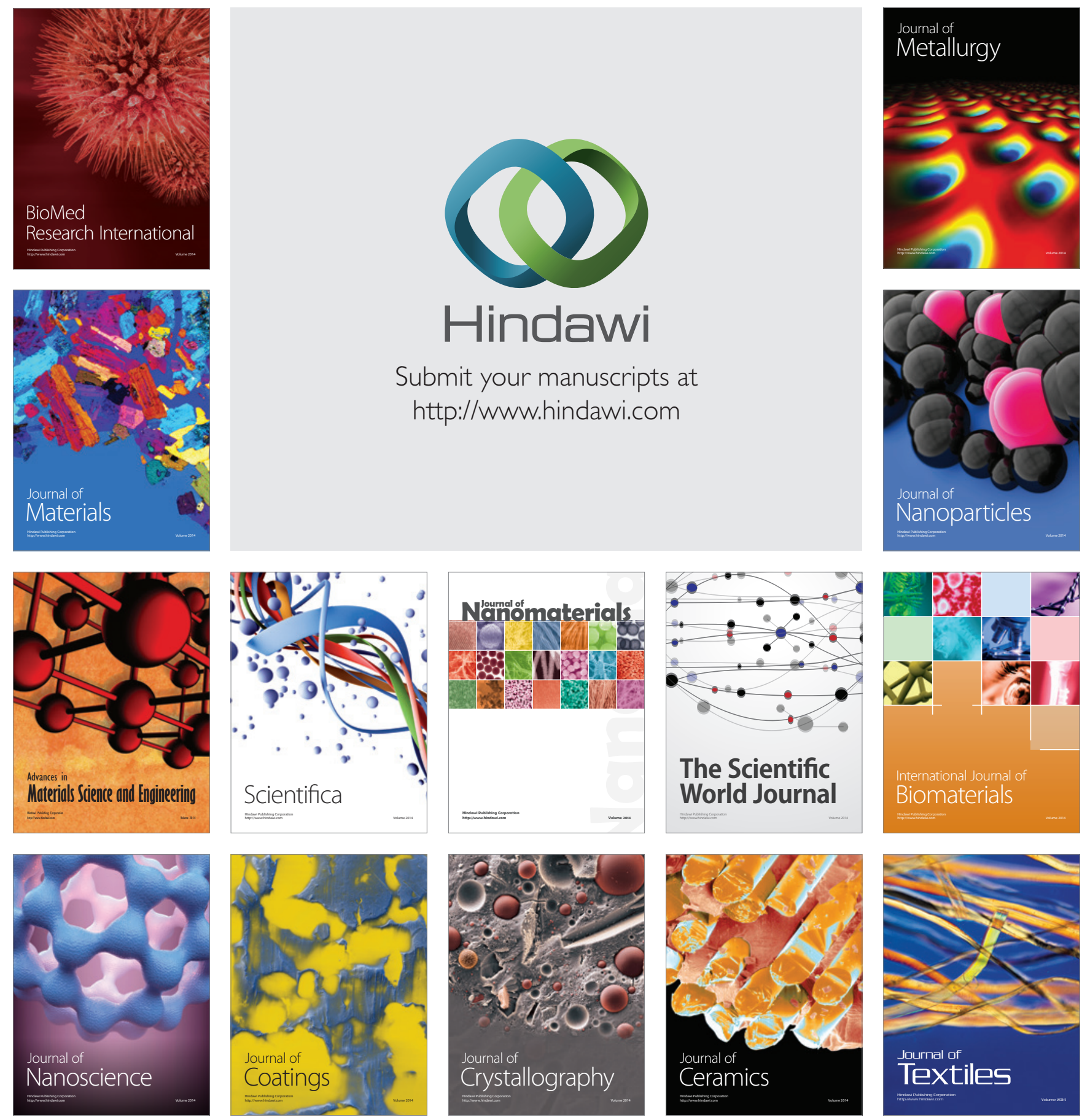